\title{
HYDROGEN PEROXIDE OBTAINED VIA DIRECT SYNTHESIS AS ALTERNATIVE RAW MATERIAL FOR ULTRAPURIFICATION PROCESS TO PRODUCE ELECTRONIC GRADE CHEMICAL
}

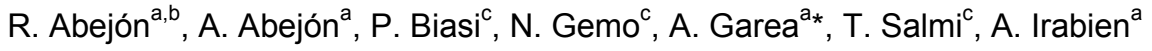

a Departamento de Ingenierías Química y Biomolecular, Universidad de Cantabria, Avda. Los Castros s/n, 39005 Santander, Spain.

b Institut Européen des Membranes (IEM), ENSCM - UM2 - CNRS, Université de Montpellier II2, CC 047, Place Eugène Bataillon, 34095 Montpellier, France.

${ }^{c}$ Department of Chemical Engineering, Åbo Akademi University, Turku / Åbo FI-20500, Finland.

* Corresponding author: aurora.garea@unican.es

Abstract

BACKGROUND:

The catalytic direct synthesis of hydrogen peroxide is a highly interesting alternative process to avoid the current anthraquinone route because implies significant sustainability improvements. Among all the peroxide applications, its use as electronic chemical requires very low metallic content. The employment of direct synthesis peroxide as raw material for ultrapurification process has not been investigated before, so its viability is still pending of evaluation.

RESULTS:

Although the improvements of the catalyst or reactor performances of the direct synthesis process were not defined as objectives of the work, a maximal peroxide concentration of $2.3 \%$ was obtained, which is a very good result considering the low pressure used. Some relationships between the measured metallic concentrations in the obtained chemical and the operation conditions have been very useful to identify the most important conditions (selection of appropriate quality for the chemicals and proper materials for the installation) to promote the production of hydrogen peroxide with low metallic content. The technical competitiveness of this alternative ultrapurification process was clearly demonstrated as the number of required membrane stages (from 1 to 6 depending on the product quality) is lower than the required one by the traditional case. Besides, the process can be considered economically viable if the direct synthesis peroxide can be produced with a total cost below 36.5 $\$ / \mathrm{m}^{3}$.

CONCLUSION:

Further investigation, specifically focused to holistic approaches, is still necessary in order to assess the total costs of hydrogen peroxide production by direct synthesis. This way, the current available information could be complemented and the competitiveness of this direct route to obtain hydrogen peroxide for electronic grade chemical production could be more clearly defined.
\end{abstract}

Keywords: Hydrogen peroxide, Direct synthesis, Ultrapurification, Viability analysis, Cost analysis.

This article has been accepted for publication and undergone full peer review but has not been through the copyediting, typesetting, pagination and proofreading process, which may lead to differences between this version and the Version of Record. Please cite this article as doi: $10.1002 /$ jctb.4699 


\section{Introduction}

\subsection{Direct synthesis of hydrogen peroxide}

Hydrogen peroxide is an oxidizing agent used in many industrial applications such as in water treatment, textile production and paper industries. Its utilization is very attractive from the environmental point of view: being the simplest of the peroxides, its oxidation potential is high, it is very selective and the unique by-products are water and oxygen ${ }^{1}$.

However, the most common method to produce $\mathrm{H}_{2} \mathrm{O}_{2}$ is not very environmentally friendly: over $95 \%$ of the current industrial production of $\mathrm{H}_{2} \mathrm{O}_{2}$ is carried out via the anthraquinone route (Riedl-Pfleiderer process) which requires toxic solvents and gives rise to high-energy consumption ${ }^{2,3}$. For this reason, an alternative process called catalytic direct synthesis (CDS) of $\mathrm{H}_{2} \mathrm{O}_{2}$ is of high interest. The reaction is based on the formation of $\mathrm{H}_{2} \mathrm{O}_{2}$ starting from the basic components $\mathrm{O}_{2}$ and $\mathrm{H}_{2}$. Typical catalyst materials identified until today to promote the CDS are supported noble metals, mainly Pd, $\mathrm{Au}, \mathrm{Au}-\mathrm{Pd}$ or Pd-Pt ${ }^{4-9}$.

The advantages of this method are many: it allows an in-situ production, no large installations are needed such as in the synthesis with Riedl-Pfleiderer process, which involves large costs for transportation of $\mathrm{H}_{2} \mathrm{O}_{2}$ at high concentration (i.e. around $70 \% \mathrm{w} / \mathrm{w}$ ) and wastewater treatments. Highly pollutant organic solvents are avoided in the direct synthesis, as the reaction can be carried out in water or alcoholic solutions. However, there are problems related to the $\mathrm{H}_{2} \mathrm{O}_{2}$ selectivity and concentration achievable: the method unfortunately also gives rise to thermodynamically favored parallel and consecutive reactions, i.e. the direct formation of $\mathrm{H}_{2} \mathrm{O}$, the decomposition of $\mathrm{H}_{2} \mathrm{O}_{2}$ and the hydrogenation of $\mathrm{H}_{2} \mathrm{O}_{2}$ leading to water formation (Figure 1).

The addition of promoters such as halide salts and inorganic acids in the medium solution seems to increase the selectivity, thus reducing the occurrence of undesired reactions: numerous studies have been carried out, in which the effect of these enhancers have been evaluated ${ }^{10-15}$.

Recently, the productivity, selectivity and final concentration of $\mathrm{H}_{2} \mathrm{O}_{2}$, obtained in aqueous solutions containing different concentrations of phosphoric acid and sodium bromide were investigated and compared. The reactor type used was a trickle bed (TBR). This allowed to identify the optimal concentration of $\mathrm{NaBr}$ and $\mathrm{H}_{3} \mathrm{PO}_{4}$ giving rise to the maximum productivity and selectivity of $\mathrm{H}_{2} \mathrm{O}_{2}$.

Here, taking into consideration the previous experiences, the effect of the selectivity enhancers in the reaction medium was correlated with the catalyst metal leaching and the final metallic impurities content of the obtained hydrogen peroxide. In this way, a new important point of view can be added to the CDS scenario. 


\subsection{Ultrapure hydrogen peroxide}

Electronic chemicals, which are the chemicals and materials used to manufacture and package semiconductors and printed circuit boards, require extreme low content of metallic impurities to minimize reliability problems in microdevices. In order to avoid contamination because of the chemicals themselves, ultrapurification processes become necessary to achieve these exigent limits. Hydrogen peroxide $\left(\mathrm{H}_{2} \mathrm{O}_{2}\right)$ is one of the most employed liquid phase electronic chemicals, which are also called wet chemicals, because it is employed for cleaning silicon wafer surfaces of organic matter, particulated contamination and metallic impurities. It is also useful to remove photoresists and etch copper on printed circuit boards. For the particular case of hydrogen peroxide, the requirements imposed to be accepted as electronic grade chemical are defined by the SEMI C30-1110 Document ${ }^{16}$, as well as the SEMI PV36-0912 Document for photovoltaic applications ${ }^{17}$. These standards were developed by the SEMI organization, which is the global industry association serving the manufacturing supply chains for the microelectronic, display and photovoltaic industries, and includes the main characteristics electronic grade hydrogen peroxide must fulfill.

Reverse osmosis membrane processes have demonstrated their technical and economic viability for hydrogen peroxide ultrapurification from technical grade chemical to semiconductor requirements ${ }^{18,19}$. Both polyamide (PA) and cellulose acetate $(C A)$ reverse osmosis membranes have been tested for this purpose ${ }^{20}$. These types of membranes show very different characteristics, specifically when they are applied to separation processes in such an oxidant medium as concentrated hydrogen peroxide. Both permeate productivity and solute removal efficiency of PA membranes can be considered higher than those of CA membranes. However, the chemical resistance of CA membranes is the property that counterbalances their performance drawbacks, as CA membranes exhibit comparatively better long-term stability under oxidative conditions than PA membranes. Nevertheless, PA membranes have demonstrated better competitiveness and should be preferred over CA membranes.

Membrane cascades can be very useful to implement demanding separation processes when moderate rejection limits the application of a single membrane stage ${ }^{21-23}$. Integrated countercurrent cascades combine high selectivity for solute removal and elevated mass yield and they have been successfully applied to wet chemicals ultrapurification ${ }^{24}$.

Therefore, the evaluation of membrane cascades which resource to hydrogen peroxide produced via direct synthesis as alternative raw material instead of the chemical obtained by the conventional anthraquinone route was carried out in order to determine their technical and economic viability.

\section{Experimental}




\subsection{Materials}

The catalyst used was $5 \mathrm{wt} . \% \mathrm{Pd}$ on an activated carbon support from Sigma-Aldrich. At the beginning of each experiment, the finely dispersed catalyst was weighted and mixed homogenously with inert quartz sand micro particles of 150-200 $\mu \mathrm{m}$ size (Merck), thus the mixture was directly fed in the reactor and used as the catalytic bed. Gaseous reagents used for the direct synthesis were pure $\mathrm{O}_{2}$ and $5 \% \mathrm{~mol} \mathrm{H}_{2} / \mathrm{CO}_{2}$ (AGA 5.0) and the liquid medium consisted of deionised water $(18.2 \mathrm{M} \Omega / \mathrm{cm}$ ). Sodium bromide (Fluka, 99.5\%) and phosphoric acid (Sigma-Aldrich, 99\%) were used as promoters, which were dissolved in the liquid inlet stream. Potassium iodide (Merck, 99.5\%), sulphuric acid (Baker, 95-97\%), ammonium molybdate tetrahydrate (Fluka, 99\%), sodium thiosulfate pentahydrate (Sigma-Aldrich, 99.5\%) and starch (Merck) were used for titration analysis.

\subsection{Experimental setup}

The experiments were carried out in a laboratory-scale trickle bed reactor, made of AISI 316 stainless steel $\left(1.5 \mathrm{~cm}\right.$ I.D and $60 \mathrm{~cm}$ long). Two cylinders, containing $\mathrm{CO}_{2} / \mathrm{H}_{2} 95 / 5 \% \mathrm{v} / \mathrm{v}$ and pure $\mathrm{O}_{2}$ were connected to the reactor and the flows of gases were controlled by Brooks 5850E and Brooks 5850S mass flow controllers, respectively.

The reactor was fed with $2 \mathrm{~cm}$ of glass wool at the bottom to avoid loss of solid material, a catalytic bed made with $120 \mathrm{~g}$ of quartz sand mixed with $150 \mathrm{mg}$ of $5 \% \mathrm{Pd} / \mathrm{C}$, and an upper part (static mixer), consisting of $30 \mathrm{~g}$ of inert quartz sand. The reactor was operated in continuous down-flow co-current mode (gas and liquid phase). The liquid was fed in the reactor at room temperature, using an Eldex Model 1 Optos HPLC pump; the entrance of the liquid phase was inside the pure quartz sand to avoid mal-distribution of the liquid phase. The gas, on the other hand, entered into small void volume (ca. 3 $\mathrm{mL}$ ) acting as pressure compensator and gas distributor.

The liquid flow into the reactor was periodically checked through a weight scale positioned under the vessel containing the working solution. The system was operated isothermally, and the temperature was kept constant using a heating/cooling jacket, allowing temperatures between -20 and $60{ }^{\circ} \mathrm{C}$. The pressure inside the reactor was controlled using a GO BP-66 back-pressure automatic controller, installed at the liquid-gas outlet. Gas-liquid mixture from the reactor flowed in a glass flask working like a flash vessel, thus separating the liquids and gases: the liquid was stored inside the flask while the gas was flowing outside through exhaust port (i.e. in this case a simple pipe); gas samples could be taken via a porous septum installed on the pipe. A manual three-way ball valve was used to sample the instantaneous liquid phase and located between the back-pressure controller and the flask. 
A constant pressure of 26 bar was selected, corresponding to the maximum pressure achievable in our lab-scale reactor. The gas was fed directly to the reactor from two different cylinders: one containing pure oxygen and the other one containing $5 \% \mathrm{H}_{2} / \mathrm{CO}_{2}$ mixture. The supplied gas mixture had the composition of 4:20:76 $=\mathrm{H}_{2}: \mathrm{O}_{2}: \mathrm{CO}_{2}(\% \mathrm{v} / \mathrm{v})$, where upon $\mathrm{H}_{2} / \mathrm{CO}_{2}$ and $\mathrm{O}_{2}$ were initially fed inside for 3 minutes to stabilize the internal pressure and, after that, the liquid was fed in the reactor and the reaction commenced. This was considered as the start of the reaction $t=0\left(t_{0}\right)$. After $t_{0}$, the liquid flow rate was maintained at $1 \mathrm{~mL} / \mathrm{min}$ until the reactor was completely filled, and the first drop was seen at the reactor outlet (it took from 40 to 50 minutes for the entire reactor to be filled by the liquid phase), after which the feed was reduced to $0.25 \mathrm{~mL} / \mathrm{min}$ and maintained constant until the end of the experiment. Liquid and gas samples were taken periodically ( every 20 minutes) and the reaction was run for 300 minutes. The liquid samples were withdrawn as follows: $\sim 1 \mathrm{~mL}$ was withdrawn from the ball valve, $700 \mu \mathrm{L}$ were transferred, through a precision pipette, in a pre-weighed sample-tube, weighted and analyzed with an iodometric titration in order to measure the $\mathrm{H}_{2} \mathrm{O}_{2}$ concentration. Gas samples were taken every 20 minutes, from the time of the first drop until the end of the reaction. A long pipe with a porous septum was connected to the final flash vessel; $100 \mu \mathrm{L}$ of gas were sucked up across the septum, with a Hamilton syringe, and analyzed by gas chromatography (GC) in order to identify the amounts of $\mathrm{H}_{2}, \mathrm{O}_{2}$ and $\mathrm{CO}_{2}$ leaving the system $\left(\mathrm{H}_{2}, \mathrm{O}_{2}\right.$ reacted and $\mathrm{CO}_{2}$ as the inert-constant phase). Agilent $6890 \mathrm{GC}$ with Porapak and Molsieve columns was applied; the carrier was helium and the detector was a TCD settled at $250^{\circ} \mathrm{C}$.

The $\mathrm{H}_{2} \mathrm{O}_{2}$ conversion was defined as follows:

$$
\mathrm{H}_{2} \mathrm{O}_{2} \text { conversion }(\%)=\frac{\mathrm{H}_{2} \text { in }-\mathrm{H}_{2} \text { out }(\mathrm{mol})}{\mathrm{H}_{2} \text { in }(\mathrm{mol})}
$$

The pHs were measured in the water solutions at atmospheric pressure before feeding them to the reactor. This was done in order to give a clear effect of the selectivity enhancers on the direct synthesis rather than the effect of the acidification by carbon dioxide. Notwithstanding, the effect of carbon dioxide can be assumed negligible when acids are used to acidify water. For these reasons the $\mathrm{pHs}$ measured in the present work do not take into account the effect of the carbon dioxide as enhancer to acidify water solutions.

\subsection{Metallic content analysis}

The characterization by ICP-MS (Agilent 7500ce system with special sample introduction system ESI Upgrade Kit made of PFA for resistance to hydrogen peroxide) of the hydrogen peroxide samples obtained by direct synthesis for the 21 metals required in SEMI C 30 and PV36 standards was carried out ${ }^{16,17}$. Palladium was also included in the characterization as it is the most important element of the employed catalyst. Some alkali ( $\mathrm{Na}$ and $\mathrm{K}$ ) and alkaline earth ( $\mathrm{Mg}$ and $\mathrm{Ca}$ ) metals were not correctly 
measured during the characterization trials, so their results were not considered. Besides, the use of $\mathrm{NaBr}$ as promoter for the direct synthesis reaction adulterates the total $\mathrm{Na}$ content of the samples. Further work to obtain more precise results for these elements by other analytical techniques (mainly IC) is planned.

\subsection{CAPE tools}

The Aspen Tech software was the CAPE tool selected to simulate the behavior of the designed membrane cascade process for the ultrapurification of hydrogen peroxide. The simulation of the proposed membrane cascades, which cover the overall and component material balances and the transport equations through the reverse osmosis membranes, was developed in the Aspen Custom Modeler environment.

GAMS software was selected as optimization tool to manage the resulting nonlinear programming (NLP) models using BARON solver. The General Algebraic Modeling System (GAMS) is a high-level modeling system for mathematical programming and optimization. It consists of a language compiler and a stable of integrated high-performance solvers.

\section{Results and discussion}

\subsection{CDS experiments}

The experiments were designed aiming at discovering a relation between the enhancers used during the direct synthesis $\left(\mathrm{NaBr}, \mathrm{H}_{3} \mathrm{PO}_{4}\right.$ and $\mathrm{H}_{2} \mathrm{SO}_{4}$ ), the metals leached from the catalyst used and the total metallic content of the produced chemical. The experiments were performed keeping the $\mathrm{H}_{2}$ conversion at $100 \%$. Selectivity was not measured since the aim of the work was not to improve the catalyst or reactor performances but to understand the potential applications of the direct synthesis for ultrapure $\mathrm{H}_{2} \mathrm{O}_{2}$. A maximum $\mathrm{H}_{2} \mathrm{O}_{2}$ concentration of 2.3 wt.\% was obtained. This is a very good result considering the low pressure used, moreover, the concentration obtained can be of potential interest for end users ${ }^{3}$.

The experimental conditions used for the $\mathrm{H}_{2} \mathrm{O}_{2}$ direct synthesis and the results obtained are reported in Table 1. The Table 1 gives an idea on the effect of the sodium bromide and the acids used during the CDS. First of all it can be seen that adding the acid, to the reaction medium containing a fixed amount of $\mathrm{NaBr}$, has a beneficial effect on the direct synthesis (Runs $\# 1$ to $\# 5$ and $\# 11, \# 12$ ), secondly, that using different acids resulted in a different $\mathrm{pH}$ but a similar production of $\mathrm{H}_{2} \mathrm{O}_{2}$ (Runs \#8 and \#9), and that the increase in $\mathrm{NaBr}$ concentration resulted in a higher $\mathrm{H}_{2} \mathrm{O}_{2}$ production (Runs \#1, 
\#6 and \#7). The optimal $\mathrm{pH}$ for the production of $\mathrm{H}_{2} \mathrm{O}_{2}$ seems to be 2.5 , as already reported in literature ${ }^{15}$.

The increase of the acid concentration in the working solution (with a fixed $\mathrm{NaBr}$ concentration of $0.005 \mathrm{M}$ ) resulted in an increase in the $\mathrm{H}_{2} \mathrm{O}_{2}$ concentration at the outlet of the reactor (Figure 2).

The increase of $\mathrm{H}_{2} \mathrm{O}_{2}$ concentration seems to be influenced by the acid up to a $\mathrm{H}_{3} \mathrm{PO}_{4}$ concentration of $0.003 \mathrm{M}$, after this value the $\mathrm{H}_{2} \mathrm{O}_{2}$ concentration is not anymore increased despite higher acid concentration. The increase in acid concentration did not result in a linear increase of $\mathrm{pH}$ when $\mathrm{H}_{3} \mathrm{PO}_{4}$ was used. Moreover, around a pH of 2.5 the production of $\mathrm{H}_{2} \mathrm{O}_{2}$ reached a plateau. This is probably the result of the incomplete dissociation of $\mathrm{H}_{3} \mathrm{PO}_{4}$ and its interaction with the $\mathrm{NaBr}$. Finally, increasing the $\mathrm{H}_{3} \mathrm{PO}_{4}$ concentration over $0.003 \mathrm{M}$ did not have a beneficial effect on the direct synthesis. This result has to be related to the metal leaching as important factor in deciding the operational conditions for the CDS. It should be underlined that this effect is seen when $0.005 \mathrm{M} \mathrm{of} \mathrm{NaBr}$ is used in the working solution. Experiments done without using $\mathrm{NaBr}$ but with the only an acid enhancer resulted in a negligible production of $\mathrm{H}_{2} \mathrm{O}_{2}$.

The concentration of $\mathrm{NaBr}$ in the working solution is proportional to the $\mathrm{H}_{2} \mathrm{O}_{2}$ production as reported in Figure 3 (without acid enhancers).

These experiments were needed to see the effect of the $\mathrm{NaBr}$ on the reaction to confirm that the bromide anion is the real promotor of the CDS while the acids enhance the effect of the bromide. It is clear from Figure 3 that the $\mathrm{H}_{2} \mathrm{O}_{2}$ concentration is almost doubled with a 4-fold increase of the $\mathrm{NaBr}$ concentration.

Another important aspect is that the $\mathrm{H}_{2} \mathrm{O}_{2}$ concentration does not increase linearly decreasing the $\mathrm{pH}$. Figure 4 shows as in the interval of $\mathrm{pH}$ between 6.5 and 3.0 there is a constant $\mathrm{H}_{2} \mathrm{O}_{2}$ production while around a $\mathrm{pH}$ of 2.5 there is a maximum in $\mathrm{H}_{2} \mathrm{O}_{2}$ production whatever is the acid used (with a fixed concentration of $\mathrm{NaBr}$ ). This is another evidence which confirms that the roles of bromide and the acids are strictly interconnected and that the CDS to be effectively promoted needs both enhancers. The results of the direct synthesis are correlated to the metal content of the produced chemical in the next section.

To be noted that in the present work the $\mathrm{H}_{2} \mathrm{O}_{2}$ selectivity was not so high as in our previous works and varied between $20 \%$ up to $42 \%$ with a $\mathrm{H}_{2}$ conversion between $65 \%$ and $90 \%$. The present work was focused in obtaining a correlation between the quantity of acid and bromide used in the reaction environment and the metal impurities at the reactor outlet. High selectivities can be achieved with different strategies as we have already demonstrated varying quantity of catalyst, catalyst distribution along the reactor bed, temperature, pressure and gas-liquid flow rates ${ }^{7}$. The focus of the work was to 
compare the $\mathrm{H}_{2} \mathrm{O}_{2}$ produced via classical auto-oxidation process with the direct synthesis, as raw material, for ultrapurification process to produce electronic grade chemical.

\subsection{Metal concentrations}

The results of the characterization are compiled in Tables 2 and 3, where samples and blanks concentrations are compiled respectively. The elements with concentrations mainly below $1 \mathrm{ppb}$ and even in some cases with values below the corresponding detection limits of the equipment $(\mathrm{Li}, \mathrm{V}, \mathrm{Zn}$, $\mathrm{As}, \mathrm{Cd}, \mathrm{Sn}, \mathrm{Sb}, \mathrm{Ba}$ and $\mathrm{Pb}$ ) were not object of further analysis and their concentrations were not included in the corresponding tables. It can be observed a broad range of concentrations for the different elements, ranging from more than $650 \mathrm{ppb}$ of Fe to concentrations below $1 \mathrm{ppb}$.

If the worst possible scenario (maximal concentration for each element) was taken into account, the resulted hydrogen peroxide exceeded the fixed limits of the less stringent electronic grade (Grade 1) in SEMI C30 for 3 metals: Fe (100 ppb), Ti (100 ppb) and $\mathrm{Cr}(50 \mathrm{ppb})$. An additional metal was included in this list when the limits of SEMI PV36 Grade 1 were analyzed: Al (100 ppb). Besides, when compared with the more demanding grades as Grade 2 for both SEMI documents, all the analyzed elements ( $\mathrm{Al}, \mathrm{B}, \mathrm{Cr}, \mathrm{Cu}, \mathrm{Fe}, \mathrm{Mn}, \mathrm{Ni}$ and $\mathrm{Ti}$ ) were above the fixed limit (10 ppb), which is a common value for both standards.

The dependence relationships between the metallic content of the hydrogen peroxide and the operation conditions implemented for its production were analyzed. The concentrations of the three

different promoters $\left(\mathrm{H}_{3} \mathrm{PO}_{4}, \mathrm{H}_{2} \mathrm{SO}_{4}\right.$ and $\left.\mathrm{NaBr}\right)$ were considered as the main experimental variables to be investigated, but these conditions determine other two important resulting conditions which were included in the study too: the $\mathrm{pH}$ of the reaction medium and the concentration of the obtained hydrogen peroxide.

In a first general approach, it seemed quite difficult to find remarkable relationships between the measured metallic concentrations and the operation conditions. As an illustrating example, the Figure 5 represents the boron concentration against all the analyzed variables. As it can be observed, the existence of dependence links between the variables is not clearly evidenced since the points are very dispersed without following visibly identifiable trends. Anyway, when the dispersion of the experimental points was reduced by the calculation of average values for the samples with the same initial promoter concentration, the identification of some interrelationships became possible for some specific elements.

The palladium concentration highly depended on the $\mathrm{NaBr}$ concentration in the reaction medium as shown in Figure 6. This relationship was clearly linear for the samples. However, the content of the blanks was negligible, so it can be assured that the presence of palladium was due to the process 
and not related to the raw materials. This fact is not very surprising as this metal is the most important component of the catalyst employed for the direct synthesis reaction.

Bromides are the halides most commonly employed as promoters for direct synthesis of hydrogen peroxide. They have been found to cause a drastic decrease in the activity of Pd catalysts related to the side reactions responsible for hydrogen peroxide decomposition, increasing the selectivity toward hydrogen peroxide ${ }^{3}$. Although the reaction mechanisms involved in the bromide deactivation of the palladium catalyst have been deeply investigated ${ }^{25}$, there are not previous signs which indicate the direct relation between bromide presence and palladium leaching from the catalyst. Therefore, an indirect relationship can be more easily explained. The presence of bromide promotes the production of hydrogen peroxide solution and its stability, so higher concentrations can be achieved. These high concentrations can be the cause of the increased palladium leaching, since oxidant chemicals in acidic medium have been identified as effective extractive solutions for palladium ${ }^{26}$. To confirm this fact, the influence of the $\mathrm{pH}$ over the palladium concentration is shown in Figure 7 and the experimental results agreed with the proposed hypothesis, although in this case the linear relationship was not so clear.

Nevertheless, the case of palladium is not unique, as other elements showed a similar behavior: their maximal concentrations corresponded to the situations characterized by the highest hydrogen peroxide concentrations and the lowest $\mathrm{pH}$ values (these two circumstances were concurrent). Among the members of this group of metals, the ones included in the formulation of stainless steel, the material the reactor is made of, must be highlighted. In Figure 8, the influence of the $\mathrm{pH}$ and the hydrogen peroxide concentration over the concentrations of iron and chromium, the main components of stainless steel, is represented. Besides, other minority metals in stainless steel, such as nickel and manganese, exhibited the same trend (not shown graphs). The beneficial effects of the controlled contact between stainless steel and hydrogen peroxide in order to form an effective passivation layer which improves the pitting resistance of the material have been clearly reported ${ }^{27,28}$. However, other authors have demonstrated the potential of hydrogen peroxide and strong inorganic acids mixtures to pickle stainless steel ${ }^{29,30}$ which involves an important contribution of metallic impurities from the steel surface to the hydrogen peroxide. Therefore, special attention has to be applied to the selection of the materials for the reactor manufacturing and the treatment of the surfaces in contact with the reaction medium.

Two other metals have to be mentioned because of their significant results. The first one is aluminum. Although it did not show a clear relationship between its concentration and the $\mathrm{pH}$ value, a quite straightforwardly recognizable correlation with the sulfuric acid concentration was identified instead (Figure 9). The origin of aluminum is not easily linked to the employment of stainless steel, since it is not among the main components. Therefore, another material present in the installation and susceptible to be degraded by sulfuric acid should be the responsible for the aluminum content of the obtained hydrogen peroxide. The second pending metal to underline is titanium. This was the most 
singular element. In this case, the metallic content is obviously linearly dependent on the phosphoric acid concentration (Figure 10). Besides, not only the samples showed this trend, the blanks followed the same tendency with very similar values when compared to the samples. This behavior can be explained if the chemical (phosphoric acid) is considered as the main source of the titanium impurities, never minding the other operation conditions of the reaction process. However, the last pair of points, those ones corresponding to the highest acid concentration, fell out of the linear trend and exhibited very low titanium content. Maybe this fact can be justified by the employment of a different phosphoric acid bottle or a different procedure to transfer the chemical. Nevertheless, it is clear that the selection of appropriate quality for the chemicals to be used as raw materials and the design of correct protocols to minimize the transfer of metallic impurities are important issues in order to achieve the desired conditions for intend the hydrogen peroxide to ultrapurification.

\subsection{Simulation}

The Aspen Custom Modeler software was employed to simulate the behavior of $n$-stage membrane cascades for hydrogen peroxide ultrapurification (Figure 11). The proposed simulation model is based on the Kedem-Katchalsky equations for solvent and solute transport through reverse osmosis membranes and overall and component material balances.

Firstly, the overall and component (metal) material balances for each stage are composed:

$$
\begin{aligned}
& \text { Initial stage (1) } \begin{array}{c}
\mathrm{F}+\mathrm{R} 2=\mathrm{F} 1 \\
\mathrm{FC}_{\mathrm{F}}^{\text {metal }}+\mathrm{R} 2 \mathrm{C}_{\mathrm{R} 2}^{\text {metal }}=\mathrm{F} 1 \mathrm{C}_{\mathrm{F} 1}^{\text {metal }} \\
\mathrm{F} 1=\mathrm{P} 1+\mathrm{R} 1 \\
\mathrm{~F} 1 \mathrm{C}_{\mathrm{F} 1}^{\text {metal }}=\mathrm{P} 1 \mathrm{C}_{\mathrm{P} 1}^{\text {metal }}+\mathrm{R} 1 \mathrm{C}_{\mathrm{R} 1}^{\text {metal }} \\
\mathrm{P}(\mathrm{i}-1)+\mathrm{R}(\mathrm{i}+1)=\mathrm{F}(\mathrm{i}) \\
\text { Intermediate stages (i) } \quad \mathrm{P}(\mathrm{i}-1) \mathrm{C}_{\mathrm{P}(\mathrm{i}-1)}^{\text {metal }}+\mathrm{R}(\mathrm{i}+1) \mathrm{C}_{\mathrm{R}(\mathrm{i}+1)}^{\text {metal }}=\mathrm{F}(\mathrm{i}) \mathrm{C}_{\mathrm{F}(\mathrm{i})}^{\text {metal }} \\
\mathrm{F}(\mathrm{i})=\mathrm{P}(\mathrm{i})+\mathrm{R}(\mathrm{i}) \\
\mathrm{F}(\mathrm{i}) \mathrm{C}_{\mathrm{F}(\mathrm{i})}^{\text {metal }}=\mathrm{P}(\mathrm{i}) \mathrm{C}_{\mathrm{P}(\mathrm{i})}^{\text {metal }}+\mathrm{R}(\mathrm{i}) \mathrm{C}_{\mathrm{R}(\mathrm{i})}^{\text {metal }} \\
\mathrm{P}(\mathrm{n}-1)=\mathrm{F}(\mathrm{n}) \\
\mathrm{P}(\mathrm{n}-1) \mathrm{C}_{\mathrm{P}(\mathrm{n}-1)}^{\text {metal }}=\mathrm{F}(\mathrm{n}) \mathrm{C}_{\mathrm{F}(\mathrm{n})}^{\text {metal }} \\
\mathrm{F}(\mathrm{n})=\mathrm{P}+\mathrm{R}(\mathrm{n}) \\
\mathrm{F}(\mathrm{n}) \mathrm{C}_{\mathrm{F}(\mathrm{n})}^{\text {metal }}=\mathrm{P} \mathrm{C}_{\mathrm{P}}^{\text {metal }}+\mathrm{R}(\mathrm{n}) \mathrm{C}_{\mathrm{R}(\mathrm{n})}^{\text {metal }}
\end{array}
\end{aligned}
$$


The feed, permeate and retentate flows of the corresponding i membrane stage are represented by $\mathrm{F}(\mathrm{i}), \mathrm{P}(\mathrm{i})$ and $\mathrm{R}(\mathrm{i})$ respectively; $\mathrm{C}_{\mathrm{F}(\mathrm{i})}^{\text {metal }}, \mathrm{C}_{\mathrm{P}(\mathrm{i})}^{\text {metal }}$ and $\mathrm{C}_{\mathrm{R}(\mathrm{i})}^{\text {metal }}$ are the metal concentrations of the corresponding feed, permeate and retentate streams and $F$ and $P$ relate to the initial feed and final permeate streams. The material balances can be formulated in terms of mass or volume base taking into account that there is no change in the density of the aqueous hydrogen peroxide during the process operation. There is no dilution or concentration of the solution as it was checked experimentally in a previous study ${ }^{18}$.

Secondly, the characteristic variables that describe the performance of the i reverse osmosis stage, namely membranes specific permeate flux $\left(\mathrm{J}_{\mathrm{V}(\mathrm{i})}\right)$ and retention coefficient of each metal $\mathrm{R}_{(\mathrm{i})}^{\text {metal }}$ ), can be defined by direct application of the Kedem-Katchalsky equations:

$$
\begin{aligned}
\mathrm{J}_{\mathrm{V}(\mathrm{i})} & =\mathrm{L}_{\mathrm{P}}^{\prime} \Delta \mathrm{P}_{(\mathrm{i})} \\
\mathrm{R}_{(\mathrm{i})}^{\text {metal }} & =\frac{\sigma^{\text {metal }} \mathrm{J}_{\mathrm{V}(\mathrm{i})}}{\mathrm{J}_{\mathrm{V}(\mathrm{i})}+\omega^{\prime}}
\end{aligned}
$$

The applied pressure in the i stage is symbolized by $\Delta \mathrm{P}_{(\mathrm{i})}$. Once the membrane transport is defined, the characteristics of the permeate streams (flow and metal concentrations) can be calculated as function of the membrane area of the corresponding i stage $\left(A_{(i)}\right)$ :

$$
\begin{gathered}
\mathrm{P}(\mathrm{i})=\mathrm{A}_{(\mathrm{i})} \mathrm{J}_{\mathrm{V}(\mathrm{i})} \\
\mathrm{C}_{\mathrm{P}(\mathrm{i})}^{\text {metal }}=\left(1-\mathrm{R}_{(\mathrm{i})}^{\text {metal }}\right) \mathrm{C}_{\mathrm{F}(\mathrm{i})}^{\text {metal }}
\end{gathered}
$$

Finally, the recovery ratio of each module $\left(\operatorname{Rec}_{(i)}\right)$ is defined:

$$
\operatorname{Rec}_{(\mathrm{i})}=\frac{\mathrm{P}(\mathrm{i})}{\mathrm{F}(\mathrm{i})}
$$

Simulation was undertaken assuming a manufacturing plant with a target annual production aimed to electronic grade purposes of 9000 tons of hydrogen peroxide (this scale is just the same previously defined for the anthaquinone process in a previous publication ${ }^{19}$ ). When 330 operating days per year are considered, the corresponding feed flow is $24.3 \mathrm{~m}^{3} / \mathrm{d}$. Another assumption is the type of membrane: a polyamide (PA) membrane was chosen. The selected membrane (BE model) is a PA commercial membrane manufactured by Woongjin Chemical previously applied to hydrogen peroxide ultrapurification ${ }^{18}$. Its main characteristics are explained in its fact sheet ${ }^{31}$. The recovery ratios of the modules were chosen as a design variables and a value of 0.9 was selected. The applied pressure was the only remaining operation variable and it was decided to simulate the process under 40 bar, the maximum pressure recommended by the manufacturer of the BE membranes. Besides, the Kedem-Katchalsky model parameters for BE membrane in hydrogen peroxide were taken from a previous study ${ }^{20}$. 
Three cases have been studied: the average case, the most productive case and the worst case. In the first case, the average concentration of each metal was calculated. In the second case, the concentrations corresponding to the run with highest hydrogen peroxide concentration (Run \#4) were selected. For the worst case, the highest concentration of each metal was chosen.

For each case, the numbers of stages needed to obtain the different electronic grades were calculated. The results are shown in Tables 4, 5 and 6 . In the three cases, the number of stages for Grade 1 and Grade 5 (the strictest) is the same: 1 and 6, respectively. In the most productive case and in the worst case, the number of stages coincides for the rest of Grades. However, the average case needs fewer stages for Grade 2, 3 and 4.

Nevertheless, the number of membrane stages to be included in the cascades is always for all the analyzed cases lower than the required one by the ultrapurification of hydrogen peroxide obtained by traditional anthraquinone process ${ }^{19}$, so the technical competitiveness of the direct synthesis route has been clearly demonstrated.

\subsection{Optimization}

The optimization task was applied to determine the best conditions for the production of SEMI Grade 1 hydrogen peroxide in the most productive case within an economically competitive framework. The price of technical grade hydrogen peroxide $\left(\mathrm{Y}_{\text {raw }}\right)$ obtained via direct synthesis was chosen as the formulated objective function to maximize. This way, the maximal competitive production cost of the hydrogen peroxide obtained by direct synthesis can be established. To warrant a competitive process, it has been considered that the resulting profit must be, at least, equal to the one derived from the ultrapurification process for hydrogen peroxide obtained by the traditional way (anthraquinone autooxidation). This way, all the production costs below the maximal value assessed for $Y_{\text {raw }}$ will assure competitive results when compared to the anthraquinone case.

A straightforward economic model based on revenues and costs is proposed to represent the economic aspects of the process. Information about the values for all the parameters appearing in the economic model can be observed in Table 7.

The daily profit of the process (Prof) is defined as the difference between total daily revenues (Rev) and costs (TC):

$$
\text { Prof }=\text { Rev }-\mathrm{TC}
$$

The electronic grade hydrogen peroxide obtained as the permeate $(P)$ is the main product of the process, but the other output stream, the retentate $(R)$, can also be considered valuable as it could be commercialized as a by-product useful for hydrogen peroxide applications where metallic content is 
not a limiting factor. According to this approach, two different terms have to be incorporated to assess the total daily revenues:

$$
\mathrm{Rev}=\mathrm{P} \mathrm{Y}_{\mathrm{EG}}+\mathrm{R} \mathrm{Y}_{\mathrm{by}}
$$

The total daily costs of the system (TC) were calculated by the addition of the capital costs (CC) and the operation costs (OC). The capital costs are divided into the costs attributable to membranes and the costs attributable to the rest of the installation, while the operation costs were itemized into raw materials, labor, energy and maintenance costs:

$$
\begin{gathered}
\mathrm{TC}=\mathrm{CC}+\mathrm{OC} \\
\mathrm{CC}=\mathrm{CC}_{\text {memb }}+\mathrm{CC}_{\mathrm{ins}} \\
\mathrm{OC}=\mathrm{OC}_{\mathrm{raw}}+\mathrm{OC}_{\mathrm{lab}}+\mathrm{OC}_{\mathrm{en}}+\mathrm{OC}_{\mathrm{m}}
\end{gathered}
$$

The capital costs of the membrane module considering straight-line depreciation were expressed as function of the membrane area of the process:

$$
\mathrm{CC}_{\text {memb }}=\frac{\mathrm{Y}_{\text {memb }} \mathrm{A}}{\mathrm{LT}_{\text {memb }}}
$$

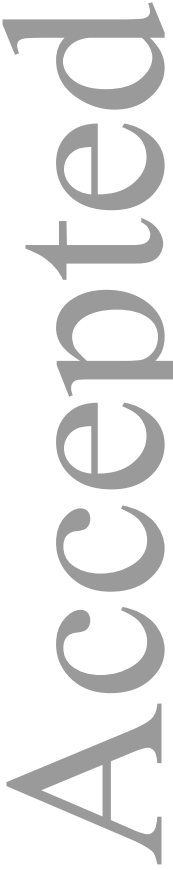

Once the membrane costs were defined, the capital costs corresponding to the rest of the installation were related to them by mean of a coefficient $\left(\mathrm{K}_{\mathrm{memb}}\right)$ that expressed the contribution of the investment in membranes to the total capital costs. The percentage of the total investment attributable to the membrane typically range between $12 \%$ and $30 \%$, so the value of $K_{\text {memb }}$ was fixed to 0.12 with the intention of representing the most disadvantageous scenario:

$$
\mathrm{CC}_{\text {ins }}=\mathrm{CC}_{\text {memb }} \frac{\left(1-\mathrm{K}_{\text {memb }}\right)}{\mathrm{K}_{\text {memb }}} \frac{\mathrm{LT}_{\text {memb }}}{\mathrm{LT}_{\text {inst }}}+\mathrm{CC}_{\text {clean }}
$$

Ultrapurification processes require contamination control, so the installation needed to be included in a cleanroom to provide the necessary controlled atmosphere. The capital costs attributable to the cleanroom ( $\mathrm{CC}_{\text {clean }}$ ) were calculated according to the model proposed by Yang and Eng Gan ${ }^{32}$ for a Class 100 space of $200 \mathrm{~m}^{2}$ (200 air changes per hour) with raised floor and FFU type air ventilation:

$$
\mathrm{CC}_{\text {clean }}=-1645051+5156.6 \mathrm{CA}+68.8 \mathrm{MAV}+34 \mathrm{EAV}+2996627 \mathrm{AFC}+\mathrm{AN}
$$

The term AN was added to include the costs related to analysis and quality control. Its value was assessed according to the previous experience in analytical equipment management when applied to chemical ultrapurification, mainly inductively coupled plasma mass spectrometry (ICP-MS) and ion chromatography (IC).

The operation costs are essentially based on the consumption of the corresponding resource, except for the case of maintenance costs, which are function of the total capital costs. The only required raw 
material was the technical grade hydrogen peroxide obtained by direct synthesis which is employed as feed and the installation was designed to be totally managed by a single worker:

$$
\begin{gathered}
\mathrm{OC}_{\text {raw }}=\mathrm{FY}_{\text {raw }} \\
\mathrm{OC}_{\text {lab }}=24 \mathrm{Y}_{\text {lab }} \\
\mathrm{OC}_{\text {en }}=\frac{\mathrm{F} \Delta \mathrm{P}}{36 \eta} \mathrm{Y}_{\text {elec }} \\
\mathrm{OC}_{\mathrm{m}}=0.05 \mathrm{CC}
\end{gathered}
$$

All the model variables have been expressed in terms of the independent design and operation variables, that is to say, recovery rate $(\operatorname{Rec})$ and applied pressure $(\Delta P)$. Constraints for the independent variables have been set as gathered in Table 8 . The valid interval of the recovery rate was defined from 0.3 to 0.9 taking into account the values referenced when membrane processes are applied to industrial installations. Recovery rate close to 1 may cause problems of polarization and recovery rate values close to 0 imply very low production rates. Related to the pressure range, it has been chosen to operate under safe conditions taking into account the maximum pressure recommended by the manufacturer of the BE membranes.

The price of the sub-product product obtained as retentate was defined as a function of the assessed price of technical grade hydrogen peroxide:

$$
\mathrm{Y}_{\mathrm{by}}=0.76 \cdot \mathrm{Y}_{\mathrm{raw}}
$$

This proportion between both prices is the same quotient that appeared for the case of the ultrapurification process from traditionally produced hydrogen peroxide.

Another circumstance to take into account was the permeate quantity. The final product flow must be adjusted to the one obtained by the anthraquinone auto-oxidation process because of their difference hydrogen peroxide concentration ${ }^{24}$. Besides, this higher dilution of the peroxide obtained via CDS implied a proportionally lower commercialization price for the ultrapure chemical $\left(\mathrm{Y}_{\mathrm{EG}}\right)$ : as it is around 14 times more diluted than the peroxide obtained by traditional route, it is around 14 times cheaper. The quality of the hydrogen peroxide was restricted to achieve the SEMI electronic Grade 1.

The Table 9 illustrates the optimization results. It was found that the optimum applied pressure was 40 bar, which is the upper boundary restriction for this variable. In a similar way, the optimum recovery rate was limited by the upper limit of the defined range (0.9).

The main cost of the process was the acquisition of the raw material that represented nearly $73 \%$ of the total costs due to the great quantity of hydrogen peroxide that it is necessary to treat (Table 10). 
The rest of the operational costs became insignificant when compared to the cost corresponding to feed hydrogen peroxide as none of them attained the $1.3 \%$ value. On the other hand, when focusing on the capital costs, the investment on membranes contributes by $13 \%$ to the total costs.

Under these conditions, the price of technical grade hydrogen peroxide could attain $48.0 \$ / \mathrm{m}^{3}$. Within this scenario, the profits obtained are equal to the ones obtained by the ultrapurification of hydrogen peroxide produced by the traditional way and, as a consequence, the process is competitive if the costs of the direct synthesis process do not exceed this calculated value.

Another optimization task was made to take into account the product quality in both processes (direct synthesis and anthraquinone auto-oxidation). In the previous optimization, hydrogen peroxide by direct synthesis was forced to fulfill the SEMI Grade requirement, but the references about ultrapure hydrogen peroxide by anthaquinone process demonstrated that the obtained product had impurity levels well below the SEMI limits. The product quality can be formulated as a dimensionless safety factor SF, defined as the quotient between the limit concentration (fixed by SEMI Standard limiting requirements) and the product concentration:

$$
\mathrm{SF}=\frac{\mathrm{C}_{\mathrm{SEMI}}}{\mathrm{C}_{\mathrm{EG}}}=\frac{\text { Failure concentration }}{\text { Design concentration }}
$$

According to the definition of the safety factor SF, each metallic solute implies a different safety factor. Nonetheless, the safety factor of the final product is the minimal value among the several individual factors corresponding to each metal. In the case of the traditional way (the anthraquinone autooxidation), the metal that established the safety factor value (5.5) was the sodium because of its high concentration in the feed. However, in the other process, the CDS, iron was found to define the safety factor value (1.1) for the same reason. Therefore, the optimization has been repeated, but including the restriction of SF value via direct synthesis equal to SF value via anthraquinone auto-oxidation (in order to obtain totally comparable products with SF 5.5) and the addition of another stage to the process because with an only stage is impossible to accomplish this new quality restriction.

The results obtained in this new optimization task are shown in the Table 11. In this case, once again, the optimum applied pressure was 40 bar for the two stages and the optimum recovery rates equal their maximal limit (0.9). Under these more exigent conditions, the price of direct synthesis hydrogen peroxide could attain $36.5 \$ / \mathrm{m}^{3}, 11.5 \$ / \mathrm{m}^{3}$ lower than the first optimization task, which imply a percent reduction close to $24 \%$. Therefore, it is clear that the inclusion of quality considerations about the obtained product imposes great challenges to the economic aspects of the direct synthesis process. Nevertheless, although some authors defend the economic viability and competitiveness of the direct synthesis process under particular conditions that include low pressure operation and small scale ${ }^{33}$, the crude reality demonstrates that holistic approaches to determine the costs of hydrogen peroxide production by direct synthesis are still required to complement some available references which publish partial results ${ }^{3}$. 


\section{Conclusions}

The main target of the work was to advance in the knowledge about the potential applications of the direct synthesis process for hydrogen peroxide production intended to obtain electronic grade chemical, and, although the improvements of the catalyst or reactor performances were not defined as objectives, the experimental results can be considered quite interesting: a maximal $\mathrm{H}_{2} \mathrm{O}_{2}$ concentration of $2.3 \%$ was obtained. This is a very good result considering the low pressure used. Therefore, the employed design can be of potential interest for end users.

Although the identification of remarkable relationships between the measured metallic concentrations in the obtained chemical and the operation conditions was not easy, some found trends have been very useful to determine the most important conditions to promote the production of hydrogen peroxide with low metallic content via direct synthesis. The selection of very high quality chemicals to be used as raw materials; the proper design of the full installation with special attention to the chosen materials and the implementation of effective protocols to minimize the transfer of metallic impurities are extremely relevant issues in order to attain the most desired conditions for the production of hydrogen peroxide as alternative raw source to further ultrapurification process.

The simulation tasks have demonstrated the technical competitiveness of the hydrogen peroxide via direct synthesis as raw source for ultrapurification process by membrane cascades. The number of membrane stages to be included in the cascades is lower than the required one when traditional anthraquinone process is employed. Besides, the optimization tasks have determined the maximal price the technical grade peroxide via CDS should have to become an economically competitive alternative: $36.5 \$ / \mathrm{m}^{3}$. Nevertheless, further holistic approaches to determine the total costs of hydrogen peroxide production by direct synthesis are still required to complement the available information.

\section{Acknowledgments}

This research has been financially supported by the Ministry of Science and Innovation of Spain (MICINN) through CTQ2010-16608 and ENE2010-14828 projects.

\section{References}


1. Eul, W.; Moeller, A.; Steiner, N. (2001). Hydrogen Peroxide. In: Kirk-Othmer Encyclopedia of Chemical Technology, Jones, C.W. (Ed). New York, Wiley.

2. Campos-Martin, J.M.; Blanco-Brieva, G., Fierro, J.L. (2006). Hydrogen peroxide synthesis: an outlook beyond the anthraquinone process. Angewandt Chemie International Edition 45:6962-6984.

3. García-Serna, J.; Moreno, T.; Biasi, P.; Cocero, M.J.; Mikkola, J.P.; Salmi T.O. (2014). Engineering in direct synthesis of hydrogen peroxide: targets, reactors and guidelines for operational conditions. Green Chemistry 16:2320-2343.

4. Biasi, P.; Menegazzo, F.; Pinna, F.; Eranen, K.; Canu, P.; Salmi, T.O. (2010). Hydrogen peroxide direct synthesis: Selectivity enhancement in a trickle bed reactor. Industrial \& Engineering Chemistry Research 49:10627-10632.

5. Biasi, P.; Menegazzo, F.; Pinna, F.; Eränen, K.; Salmi, T.O.; Canu, P. (2011). Continuous $\mathrm{H}_{2} \mathrm{O}_{2}$ direct synthesis over Pd-Au catalysts. Chemical Engineering Journal 176-177:172-177.

6. Biasi, P.; Gemo, N.; Hernández Carucci, J.R.; Eränen, K.; Canu, P.; Salmi, T.O. (2012). Kinetics and mechanism of $\mathrm{H}_{2} \mathrm{O}_{2}$ direct synthesis over a $\mathrm{Pd} / \mathrm{C}$ catalyst in a batch reactor. Industrial \& Engineering Chemistry Research 51:8903-8912.

7. Biasi, P.; Garcia-Serna, J.; Bittante, A.; Salmi, T. (2013a). Direct synthesis of hydrogen peroxide in water in a continuous trickle bed reactor optimized to maximize productivity. Green Chemistry 15:2502-2513.

8. Biasi, P.; Menegazzo, F.; Canu, P.; Pinna, F.; Salmi, T.O. (2013b). Role of a functionalized polymer (K2621) and an inorganic material (sulphated zirconia) as supports in hydrogen peroxide direct synthesis in a continuous reactor. Industrial \& Engineering Chemistry Research 52:1547215480.

9. Edwards, J.K.; Parker, S.F.; Pritchard, J.; Piccinini, M.; Freakley, S.J.; He, Q.; Carley, A.F.; Kiely, C.J.; Hutchings, G.J. (2013). Effect of acid pre-treatment on AuPd/SiO ${ }_{2}$ catalysts for the direct synthesis of hydrogen peroxide. Catalysis Science \& Technology 3:812-818.

10. Burch, R.; Ellis, P.R. (2003). An investigation of alternative catalytic approaches for the direct synthesis of hydrogen peroxide from hydrogen and oxygen. Applied Catalysis B: Environmental 42:203-211.,

11. Choudhary, V.; Samanta, C. (2006). Role of chloride or bromide anions and protons for promoting the selective oxidation of $\mathrm{H}_{2}$ by $\mathrm{O}_{2}$ to $\mathrm{H}_{2} \mathrm{O}_{2}$ over supported $\mathrm{Pd}$ catalysts in an aqueous medium. Journal of Catalysis 238:28-38.

12. Choudhary, V.R.; Samanta, C.; Jana, P. (2007). Formation from direct oxidation of $\mathrm{H}_{2}$ and destruction by decomposition/hydrogenation of $\mathrm{H}_{2} \mathrm{O}_{2}$ over $\mathrm{Pd} / \mathrm{C}$ catalyst in aqueous medium containing different acids and halide anions. Applied Catalysis A: General 317:234-243.

13. Samanta, C.; Choudhary, V.R. (2007). Direct formation of $\mathrm{H}_{2} \mathrm{O}_{2}$ from $\mathrm{H}_{2}$ and $\mathrm{O}_{2}$ and decomposition/hydrogenation of $\mathrm{H}_{2} \mathrm{O}_{2}$ in aqueous acidic reaction medium over halide-containing $\mathrm{Pd} / \mathrm{SiO}_{2}$ catalytic system. Catalysis Communications 8:2222-2228.

14. Ntainjua, N.E.; Piccinini, M.; Pritchard, J.C.; He, Q.; Edwards, J.K.; Carley, A.F.; Moulijn, J.A.; Kiely, C.J.; Hutchings, G.J. (2009). The effect of bromide pretreatment on the performance of supported Au-Pd catalysts for the direct synthesis of hydrogen peroxide. ChemCatChem 1:479-484.

This article is protected by copyright. All rights reserved 
15. Rueda, T.M.; Serna, J.G.; Alonso, M.J.C. (2011). Direct production of $\mathrm{H}_{2} \mathrm{O}_{2}$ from $\mathrm{H}_{2}$ and $\mathrm{O}_{2}$ in a biphasic $\mathrm{H}_{2} \mathrm{O} / \mathrm{ScCO}_{2}$ system over a Pd/C catalyst: Optimization of reaction conditions. Journal of Supercritical Fluids 61:119-125.

16. SEMI ${ }^{\circledR}$ Semiconductor Equipment and Material International Association (2010). Specifications for hydrogen peroxide. SEMI Document C30-1110.

17. SEMI ${ }^{\circledR}$ Semiconductor Equipment and Material International Association (2012). Specifications for hydrogen peroxide, used in photovoltaic applications. SEMI Document PV36-0912.

18. Abejón, R.; Garea, A.; Irabien, A. (2010). Ultrapurification of hydrogen peroxide solution from ionic metals impurities to semiconductor grade by reverse osmosis. Separation and Purification Technology 76:44-51.

19. Abejón, R.; Garea, A.; Irabien, A. (2012a). Integrated countercurrent reverse osmosis cascades for hydrogen peroxide ultrapurification. Computers and Chemical Engineering 41:67-76.

20. Abejón, R.; Garea, A.; Irabien, A. (2013). Effective lifetime study of commercial reverse osmosis membranes for optimal hydrogen peroxide ultrapurification processes. Industrial and Engineering Chemistry Research 52:17270-17284.

21. Siew, W.E.; Livingston, A.G.; Ates, C.; Merschaert, A. (2013). Continuous solute fractionation with membrane cascades - A high productivity alternative to diafiltration. Separation and Purification Technology 102:1-14.

22. Van Der Bruggen, B. (2013). Integrated membrane separation processes for recycling of valuable wastewater streams: Nanofiltration, membrane distillation, and membrane crystallizers revisited. Industrial and Engineering Chemistry Research 52:10335-10341.

23. Vanneste, J.; Ormerod, D.; Theys, G.; Van Gool, D.; Van Camp, B.; Darvishmanesh, S.; Van der Bruggen, B. (2013). Towards high resolution membrane-based pharmaceutical separations. Journal of Chemical Technology and Biotechnology 88:98-108.

24. Abejón, R.; Garea, A.; Irabien, A. (2012b). Optimum design of reverse osmosis systems for hydrogen peroxide ultrapurification. AIChE Journal 58:3718-3730.

25. Deguchi, T.; Iwamoto, M. (2011). Reaction mechanism of direct $\mathrm{H}_{2} \mathrm{O}_{2}$ synthesis from $\mathrm{H}_{2}$ and $\mathrm{O}_{2}$ over $\mathrm{Pd} / \mathrm{C}$ catalyst in water with $\mathrm{H}^{+}$and $\mathrm{Br}^{-}$ions. Journal of Catalysis 280:239-246.

26. Sarioglan, S. (2013). Recovery of palladium from spent activated carbon-supported palladium catalysts. Platinum Metals Review, 57:289-296.

27. Shibata, T. (2010). Increase in corrosion resistance of stainless steels by passivation treatment using $\left(\mathrm{H}_{2} \mathrm{O}_{2}+\mathrm{O}_{3}\right)$ solution. Zairyo to Kankyo / Corrosion Engineering, 59:464-467.

28. Wang, J.H.; Gu, K.L.; Wu, L.; Li, J.; Yuan, C.Q.; Li, J. (2009). Surface passivation treatment and tribological properties of $1 \mathrm{Cr} 18 \mathrm{Ni9Ti}$ stainless steel in hydrogen peroxide solution. Mocaxue Xuebao / Tribology, 29:17-24.

29. Sanders, N.J. (1997). Environmentally friendly stainless steel pickling. Anti-Corrosion Methods and Materials, 44:20-25.

30. Narváez Hernández, L.; Miranda Vidales, J.M.; Martínez-Flores, E.E. (2014). Effect of ascorbic acid on hydrogen peroxide decomposition into an environmentally friendly mixture for pickling of 316L stainless steel. Protection of Metals and Physical Chemistry of Surfaces, 50:384-390.

This article is protected by copyright. All rights reserved 
31. Woongjin Chemical Company (2007). Model RE 4040-BE Product Specification Sheet. Specification Sheet Rev. 2411112 04/15/07.

32. Yang, L.; Eng Gan C. (2007) Costing small cleanrooms. Building and Environment 42:743-751.

33. Pashkova, A.; Dittmeyer, R. (2014). Carbon dioxide as an alternative solvent for the direct synthesis of hydrogen peroxide: A review of recent activities. Catalysis Today http://dx.doi.org/10.1016/j.cattod.2014.03.012. 


\section{NOMENCLATURE}

$A_{(i)} \quad$ membrane area of the i stage $\left(\mathrm{m}^{2}\right)$

CC capital costs $(\$ / d)$

$\mathrm{CC}_{\text {clean }} \quad$ capital costs attributable to cleanroom $(\$ / \mathrm{d})$

$\mathrm{CC}_{\text {inst }} \quad$ capital costs attributable to installation ( $\left.\$ / \mathrm{d}\right)$

$\mathrm{CC}_{\text {memb }} \quad$ capital costs attributable to membranes $(\$ / \mathrm{d})$

$\mathrm{C}_{\mathrm{F}(\mathrm{i})}^{\text {metal }} \quad$ concentration of the corresponding metal in the i feed stream (ppb)

$\mathrm{C}_{\mathrm{P}(\mathrm{i})}^{\text {metal }} \quad$ concentration of the corresponding metal in the i permeate stream ( $\mathrm{ppb}$ )

$\mathrm{C}_{\mathrm{R}(\mathrm{i})}^{\text {metal }} \quad$ concentration of the corresponding metal in the i retentate stream (ppb)

F initial feed flow $\left(\mathrm{m}^{3} / \mathrm{d}\right)$

$\mathrm{F}$ (i) feed flow of the i stage $\left(\mathrm{m}^{3} / \mathrm{d}\right)$

$J_{V} \quad$ permeate flux $(\mathrm{m} / \mathrm{s})$

$J_{V(i)} \quad$ permeate flux of the i stage $(\mathrm{m} / \mathrm{d})$

$\mathrm{K}_{\mathrm{memb}} \quad$ ratio membrane capital costs to total capital costs

\begin{tabular}{|c|c|}
\hline $\mathrm{K}_{\mathrm{memb}}$ & ratio membrane capital costs to total capital costs \\
\hline$L_{P}$ & hydraulic permeability coefficient (m/s bar) \\
\hline $\mathrm{LT}_{\text {memb }}$ & membrane lifetime (d) \\
\hline $\mathrm{LT}_{\text {inst }}$ & installation lifetime $(\mathrm{d})$ \\
\hline oc & operation costs $(\$ / d)$ \\
\hline $\mathrm{OC}_{\mathrm{en}}$ & energy costs $(\$ / d)$ \\
\hline $\mathrm{OC}_{\mathrm{lab}}$ & labor costs $(\$ / d)$ \\
\hline $\mathrm{OC}_{\mathrm{m}}$ & maintenance costs $(\$ / d)$ \\
\hline $\mathrm{OC}_{\text {raw }}$ & raw material costs $(\$ / d)$ \\
\hline $\mathrm{P}$ & permeate flow of the final stage $\left(\mathrm{m}^{3} / \mathrm{d}\right)$ \\
\hline $\mathrm{P}(\mathrm{i})$ & permeate flow of the i stage $\left(\mathrm{m}^{3} / \mathrm{d}\right)$ \\
\hline Prof & daily profit $(\$ / d)$ \\
\hline $\mathrm{R}$ & rejection coefficient \\
\hline $\mathrm{R}_{(\mathrm{i})}^{\text {metal }}$ & rejection coefficient of the corresponding metal in the i stage \\
\hline $\mathrm{R}(\mathrm{i})$ & retentate flow of the i stage $\left(\mathrm{m}^{3} / \mathrm{d}\right)$ \\
\hline $\operatorname{Rec}_{(i)}$ & recovery ratio of the i stage \\
\hline Rev & daily revenues $(\$ / d)$ \\
\hline SF & safety factor \\
\hline TC & total costs $(\$ / d)$ \\
\hline$Y_{\text {by }}$ & price of by-product hydrogen peroxide from first stage retentate $\left(\$ / \mathrm{m}^{3}\right)$ \\
\hline
\end{tabular}




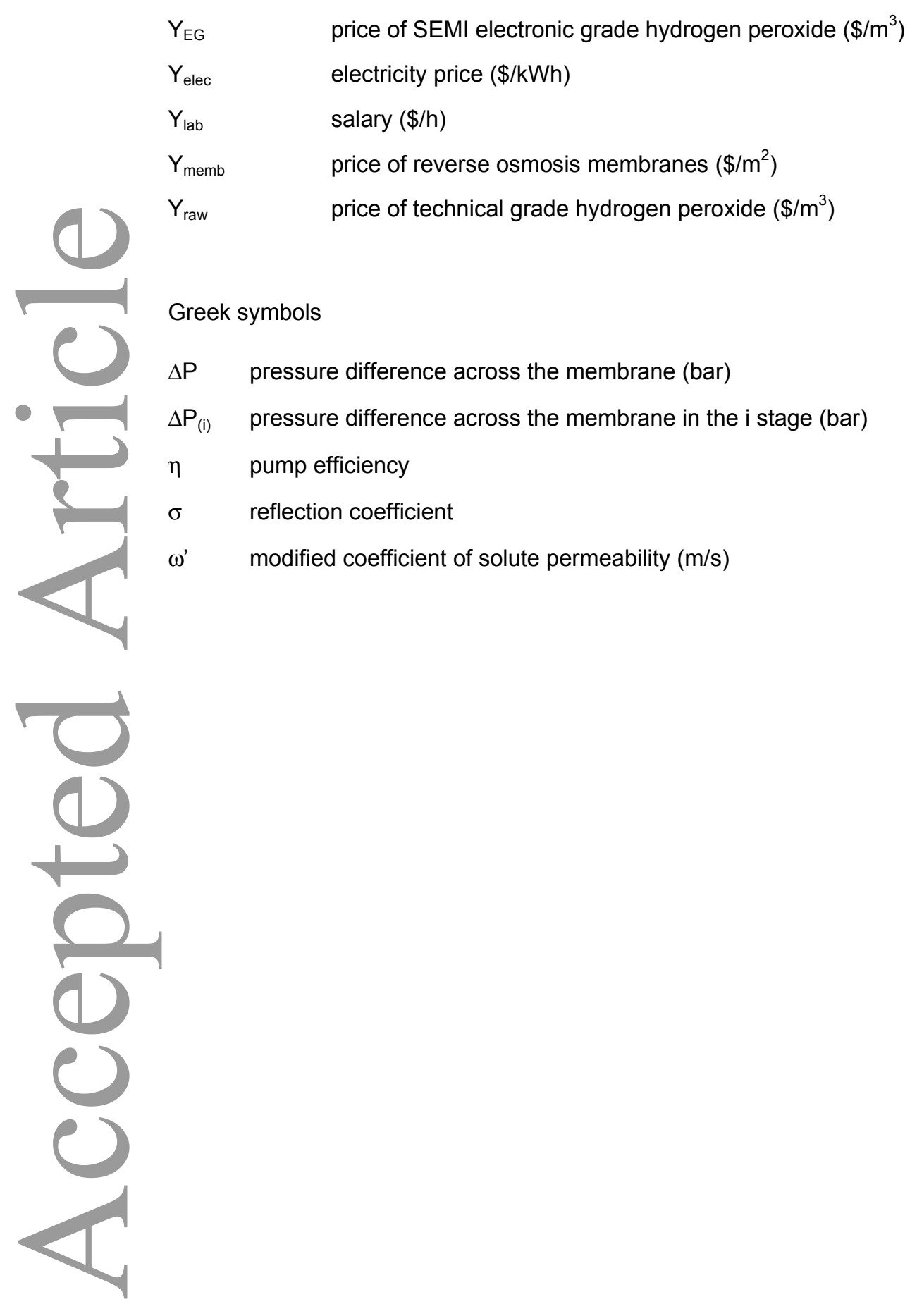


Table 1. Experimental conditions and results of the $\mathrm{H}_{2} \mathrm{O}_{2} \mathrm{CDS}$

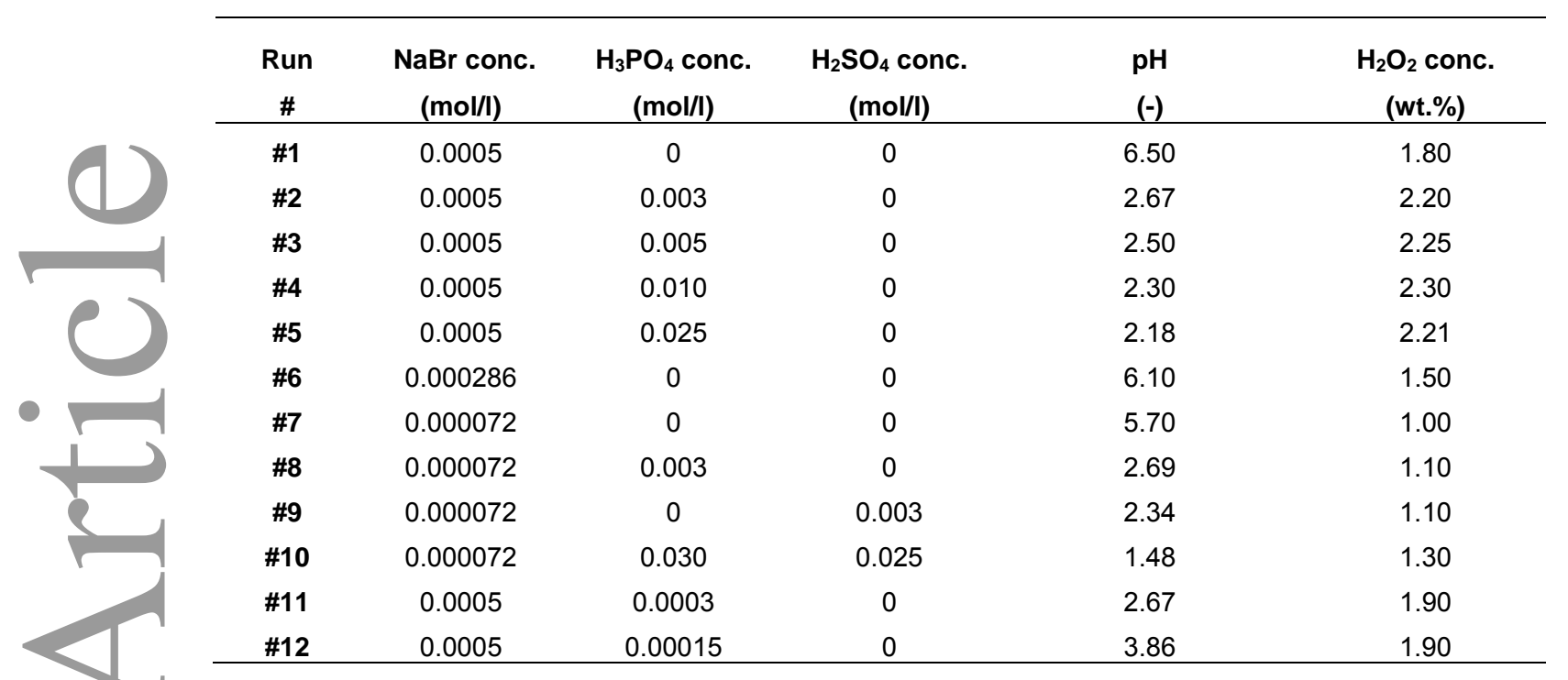


Table 2. Metal concentrations (ppb) in the samples

\begin{tabular}{crrrrrrrrr}
\hline Run \# & \multicolumn{1}{c}{ B } & \multicolumn{1}{c}{ Al } & \multicolumn{1}{c}{ Ti } & \multicolumn{1}{c}{ Cr } & Mn & \multicolumn{1}{c}{ Fe } & Ni & Cu & \multicolumn{1}{c}{ Pd } \\
\hline \#1 & 7.0 & 85.2 & 4.1 & 17.2 & 2.0 & 71.5 & 12.1 & 4.6 & 53.7 \\
\#2 & 14.4 & 141.3 & 87.7 & 51.7 & 8.5 & 437.0 & 23.4 & 9.5 & 172.9 \\
\#3 & 9.9 & 115.9 & 106.8 & 51.3 & 4.5 & 315.5 & 13.0 & 9.7 & 245.6 \\
\#4 & 7.7 & 105.9 & 172.9 & 76.4 & 18.2 & 660.4 & 41.0 & 11.1 & 195.7 \\
\#5 & 7.4 & 91.9 & 398.4 & 59.6 & 6.9 & 412.5 & 16.3 & 6.9 & 122.9 \\
\#6 & 8.0 & 141.3 & 6.4 & 17.9 & 2.6 & 29.9 & 11.9 & 9.9 & 47.5 \\
\#7 & 8.7 & 4.6 & 5.3 & 8.1 & 2.1 & 0.0 & 9.1 & 0.8 & 11.6 \\
\#8 & 13.7 & 108.0 & 18.5 & 18.6 & 2.6 & 66.0 & 11.5 & 3.6 & 5.7 \\
\#9 & 12.6 & 132.7 & 26.8 & 24.6 & 6.5 & 166.7 & 22.0 & 5.0 & 8.1 \\
\#10 & 12.6 & 196.0 & 42.8 & 75.4 & 6.5 & 445.7 & 20.6 & 10.4 & 8.8 \\
\#11 & 12.4 & 84.8 & 14.6 & 21.4 & 3.3 & 39.6 & 24.2 & 13.6 & 20.6 \\
\#12 & 7.5 & 42.8 & 6.8 & 15.2 & 1.8 & 12.6 & 11.3 & 6.7 & 14.4 \\
\hline
\end{tabular}


Table 3. Metal concentrations ( $\mathrm{ppb}$ ) in the blanks

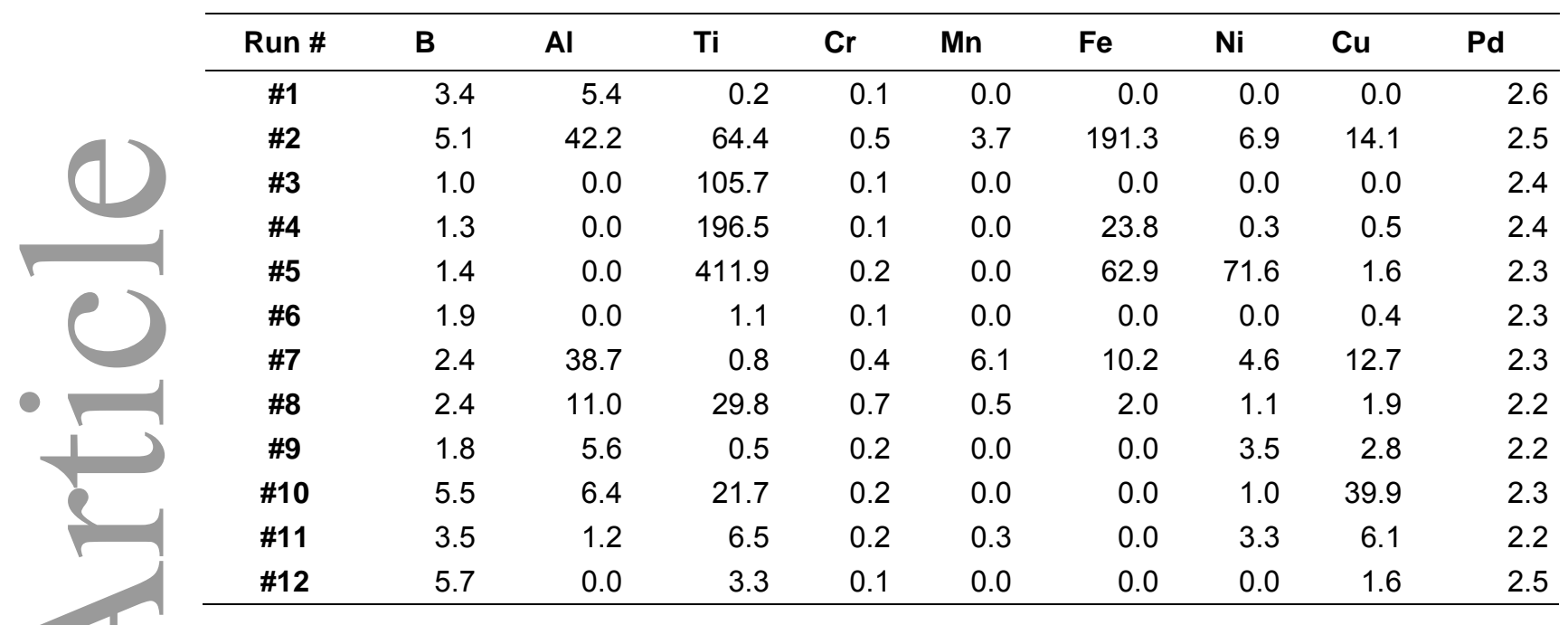


Table 4. Concentrations of each metal and the required stages for each electronic grade (Average case)

\begin{tabular}{|c|c|c|c|c|c|c|c|c|c|}
\hline & \multirow[b]{2}{*}{ Stages } & \multicolumn{8}{|c|}{ Concentration (ppb) } \\
\hline & & B & Al & $\mathrm{Ti}$ & $\mathrm{Cr}$ & Mn & $\mathrm{Fe}$ & $\mathrm{Ni}$ & $\mathrm{Cu}$ \\
\hline Grade 1 / PV Grade 1 & 1 & 2.253 & 9.955 & 7.891 & 3.928 & 0.609 & 32.285 & 1.772 & 0.426 \\
\hline Grade 2 I PV Grade 2 & 2 & 0.539 & 0.939 & 0.835 & 0.421 & 0.069 & 4.391 & 0.173 & 0.023 \\
\hline Grade 3 & 3 & 0.132 & 0.088 & 0.088 & 0.045 & 0.008 & 0.600 & 0.017 & 0.001 \\
\hline Grade 4 & 4 & 0.033 & 0.008 & 0.009 & 0.005 & 0.001 & 0.082 & 0.002 & $<0.001$ \\
\hline Grade 5 & 6 & 0.002 & $<0.001$ & $<0.001$ & $<0.001$ & $<0.001$ & 0.002 & $<0.001$ & $<0.001$ \\
\hline
\end{tabular}
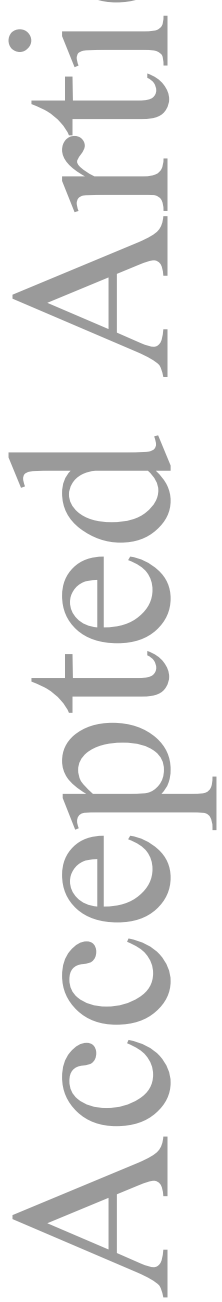
Table 5. Concentrations of each metal and the required stages for each electronic grade (Most productive case)

\begin{tabular}{|c|c|c|c|c|c|c|c|c|c|}
\hline & \multirow[b]{2}{*}{ Stages } & \multicolumn{8}{|c|}{ Concentration (ppb) } \\
\hline & & B & Al & $\mathrm{Ti}$ & $\mathrm{Cr}$ & Mn & $\mathrm{Fe}$ & $\mathrm{Ni}$ & $\mathrm{Cu}$ \\
\hline Grade 1 / PV Grade 1 & 1 & 1.701 & 10.117 & 18.363 & 8.221 & 2.051 & 88.250 & 4.047 & 0.623 \\
\hline Grade 2 I PV Grade 2 & 3 & 0.100 & 0.090 & 0.205 & 0.095 & 0.026 & 1.639 & 0.038 & 0.002 \\
\hline Grade 3 & 4 & 0.025 & 0.008 & 0.022 & 0.010 & 0.003 & 0.224 & 0.004 & $<0.001$ \\
\hline Grade 4 & 5 & 0.006 & 0.001 & 0.002 & 0.001 & $<0.001$ & 0.031 & $<0.001$ & $<0.001$ \\
\hline Grade 5 & 6 & 0.002 & $<0.001$ & $<0.001$ & $<0.001$ & $<0.001$ & 0.004 & $<0.001$ & $<0.001$ \\
\hline
\end{tabular}
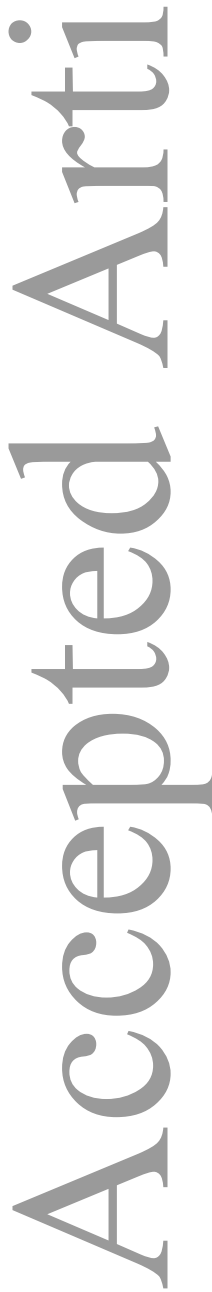
Table 6. Concentrations of each metal and the required stages for each electronic grade (Worst case)

\begin{tabular}{|c|c|c|c|c|c|c|c|c|c|}
\hline & \multirow[b]{2}{*}{ Stages } & \multicolumn{8}{|c|}{ Concentration (ppb) } \\
\hline & & B & Al & $\mathrm{Ti}$ & $\mathrm{Cr}$ & Mn & $\mathrm{Fe}$ & $\mathbf{N i}$ & $\mathrm{Cu}$ \\
\hline Grade 1 / PV Grade 1 & 1 & 3.181 & 18.725 & 42.313 & 8.221 & 2.051 & 88.250 & 4.047 & 0.763 \\
\hline Grade 2 I PV Grade 2 & 3 & 0.187 & 0.166 & 0.473 & 0.095 & 0.026 & 1.639 & 0.038 & 0.002 \\
\hline Grade 3 & 4 & 0.046 & 0.016 & 0.050 & 0.010 & 0.003 & 0.224 & 0.004 & $<0.001$ \\
\hline Grade 4 & 5 & 0.011 & 0.001 & 0.005 & 0.001 & $<0.001$ & 0.031 & $<0.001$ & $<0.001$ \\
\hline Grade 5 & 6 & 0.003 & $<0.001$ & 0.001 & $<0.001$ & $<0.001$ & 0.004 & $<0.001$ & $<0.001$ \\
\hline
\end{tabular}


Table 7. Economic model parameters.

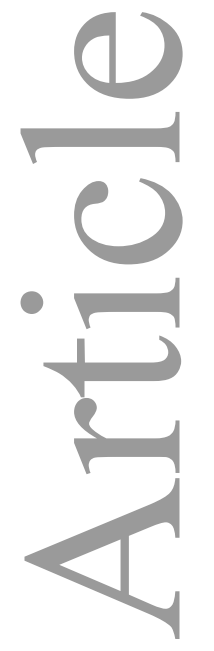

\begin{tabular}{lcr}
\hline Parameter & Unit & Value \\
\hline $\mathbf{Y}_{\text {memb }}$ & $\left(\$ / \mathrm{m}^{2}\right)$ & 50 \\
LT $_{\text {memb }}$ & $(\mathrm{d})$ & 3 \\
LT $_{\text {inst }}$ & $(\mathrm{d})$ & 1825 \\
$\mathbf{K}_{\text {memb }}$ & & 0.12 \\
$\mathbf{Y}_{\text {EG }}$ & $\left(\$ / \mathrm{m}^{3}\right)$ & 186.3 \\
$\mathbf{Y}_{\text {lab }}$ & $(\$ / \mathrm{h})$ & 7 \\
$\mathbf{Y}_{\text {elec }}$ & $(\$ / \mathrm{kWh})$ & 0.08 \\
$\eta$ & & 0.70 \\
$\mathbf{C} C_{\text {clean }}$ & $(\$ / \mathrm{d})$ & 2590 \\
\hline
\end{tabular}

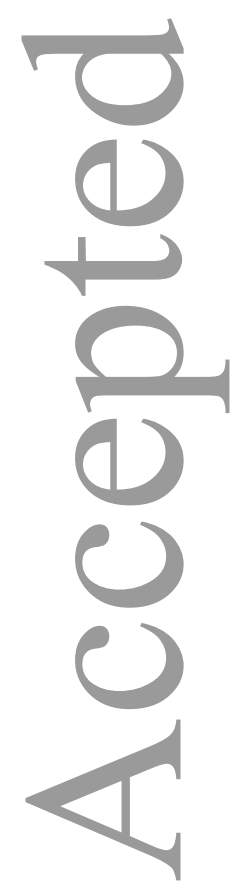


Table 8. Optimization problem formulation

\begin{tabular}{cc}
\hline Objective function & $\mathrm{Y}_{\text {raw }}$ \\
Optimization target & Maximization \\
Independent variables & $\operatorname{Rec}, \Delta \mathrm{P}$ \\
Constraints to independent variables & $0.3<\operatorname{Rec}<0.9$ \\
& $10<\Delta \mathrm{P}<40$ \\
Other constraints & Conc Prod $<$ Conc SEMI \\
\hline
\end{tabular}

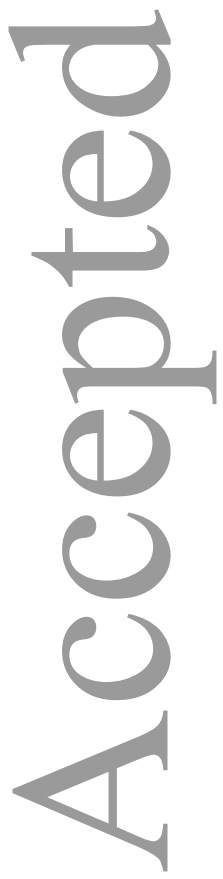


Table 9. Optimization results

\begin{tabular}{lr}
\hline Variable & Optimal value \\
\hline$\Delta P$ & 40.0 \\
$\operatorname{ReC}$ & 0.9 \\
$\mathrm{~F}\left(\mathrm{~m}^{3} / \mathrm{d}\right)$ & 332.4 \\
$\mathrm{~A}\left(\mathrm{~m}^{2}\right)$ & 176.0 \\
$\mathrm{Y}_{\text {raw }}\left(\$ / \mathrm{m}^{3}\right)$ & 48.0 \\
$\mathrm{Y}_{\text {by }}\left(\$ / \mathrm{m}^{3}\right)$ & 36.5 \\
Economic terms $(\$ / \mathrm{d})$ & \\
Prof & 34928 \\
$\operatorname{Rev}$ & 56941 \\
$\mathrm{TC}$ & 22013 \\
$\mathrm{CC}$ & 5558 \\
$\mathrm{CC}_{\text {memb }}$ & 2933 \\
$\mathrm{CC}_{\text {inst }}$ & 2625 \\
$\mathrm{OC}$ & 16455 \\
$\mathrm{OC}_{\text {raw }}$ & 15966 \\
$\mathrm{OC}_{\text {lab }}$ & 168 \\
$\mathrm{OC}_{\text {en }}$ & 42 \\
$\mathrm{OC}_{\mathrm{m}}$ & 278 \\
\hline
\end{tabular}


Table 10. Breakdown of the total costs of the optimized installation

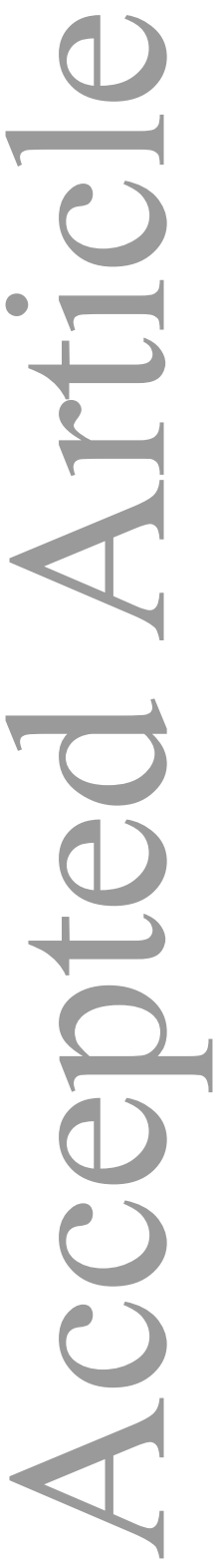

\begin{tabular}{lr} 
Cost concept & Contribution (\%) \\
\hline $\mathrm{CC}$ & 25.2 \\
$\mathrm{CC}_{\text {memb }}$ & 13.3 \\
$\mathrm{CC}_{\text {inst }}$ & 11.9 \\
$\mathrm{OC}$ & 74.8 \\
$\mathrm{OC}_{\text {raw }}$ & 72.5 \\
$\mathrm{OC}_{\text {lab }}$ & 0.8 \\
$\mathrm{OC}_{\mathrm{en}}$ & 0.2 \\
$\mathrm{OC}_{\mathrm{m}}$ & 1.3 \\
\hline
\end{tabular}


Table 11: Optimization results including SF restriction

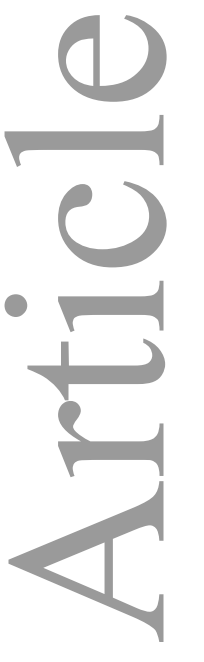

\begin{tabular}{lr}
\hline Variable & Optimal value \\
\hline$\Delta \mathrm{P}_{(1)}($ bar $)$ & 40.0 \\
$\Delta \mathrm{P}_{(2)}($ bar $)$ & 40.0 \\
$\operatorname{ReC}_{(1)}$ & 0.9 \\
$\operatorname{Rec}_{(2)}$ & 0.9 \\
$\mathrm{~F}\left(\mathrm{~m}^{3} / \mathrm{d}\right)$ & 336.1 \\
$\mathrm{~A}\left(\mathrm{~m}^{2}\right)$ & 371.5 \\
$\mathrm{Y}_{\text {raw }}\left(\$ / \mathrm{m}^{3}\right)$ & 36.5 \\
$\mathrm{Y}_{\text {by }}\left(\$ / \mathrm{m}^{3}\right)$ & 27.7 \\
$\mathrm{Economic}$ terms $(\$ / \mathrm{d})$ & \\
$\mathrm{Prof}$ & 34928 \\
$\operatorname{Rev}$ & 56752 \\
$\mathrm{TC}$ & 21824 \\
$\mathrm{CC}$ & 8856 \\
$\mathrm{CC}_{\text {memb }}$ & 6191 \\
$\mathrm{CC}_{\text {inst }}$ & 2665 \\
$\mathrm{OC}$ & 12986 \\
$\mathrm{OC}_{\text {raw }}$ & 12269 \\
$\mathrm{OC}_{\text {lab }}$ & 168 \\
$\mathrm{OC}_{\text {en }}$ & 89 \\
$\mathrm{OC}_{\mathrm{m}}$ & 443 \\
\hline & \\
&
\end{tabular}




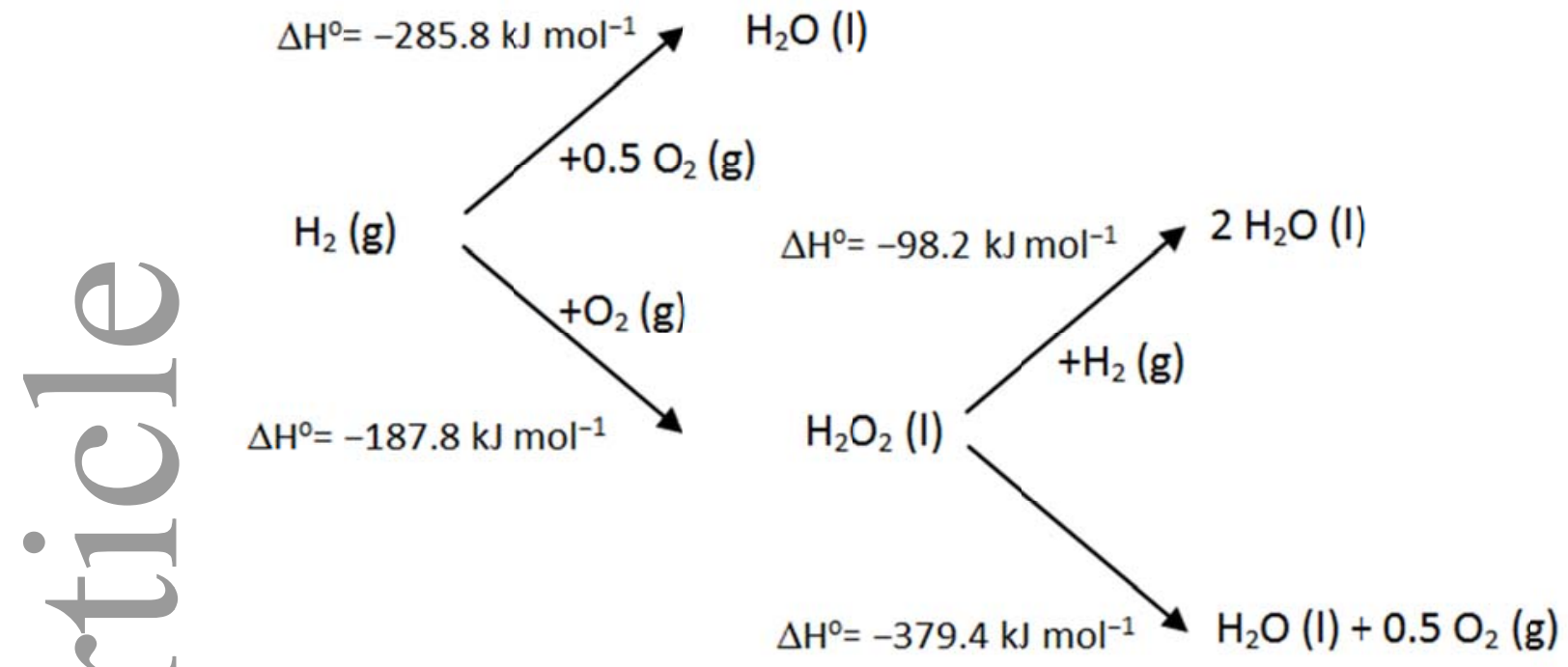

Figure 1. Direct synthesis and decomposition of hydrogen peroxide. 


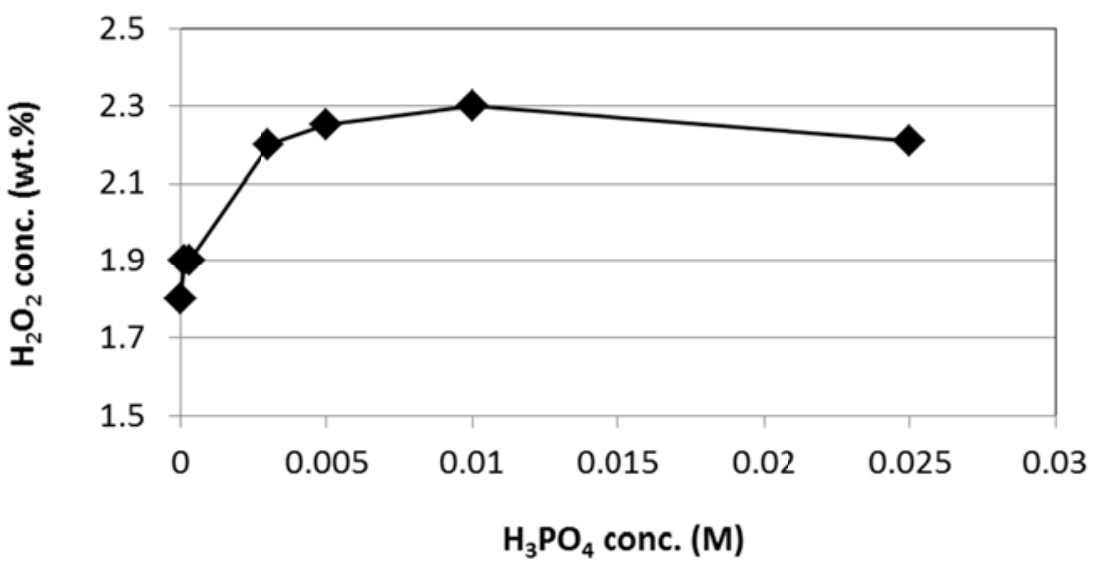

Figure 2. Influence of the $\mathrm{H}_{3} \mathrm{PO}_{4}$ concentration on the $\mathrm{H}_{2} \mathrm{O}_{2}$ formation 


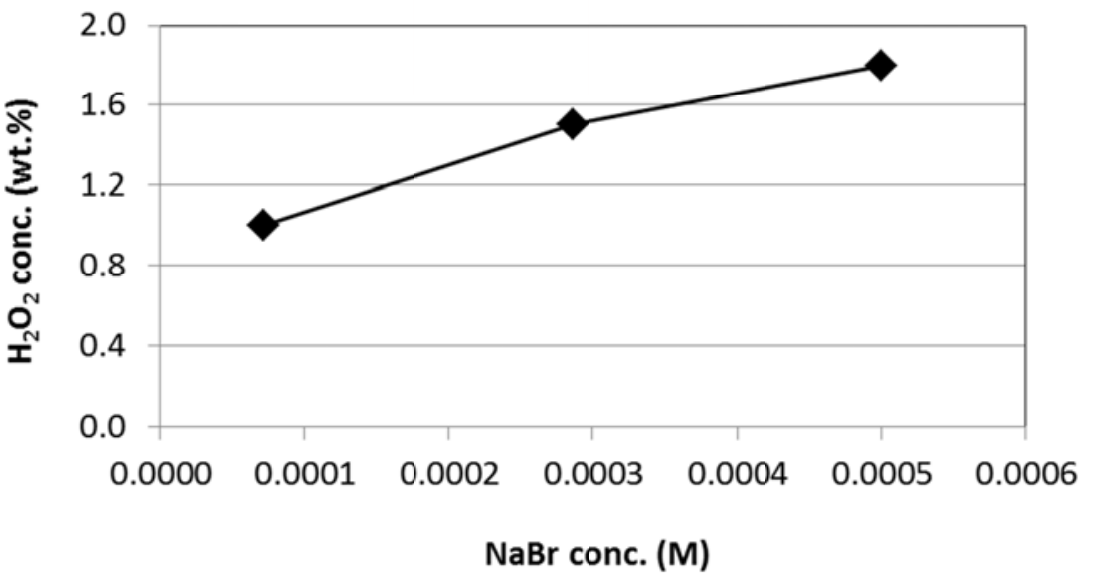

Figure 3. Influence of the $\mathrm{NaBr}$ concentration on the $\mathrm{H}_{2} \mathrm{O}_{2}$ formation 

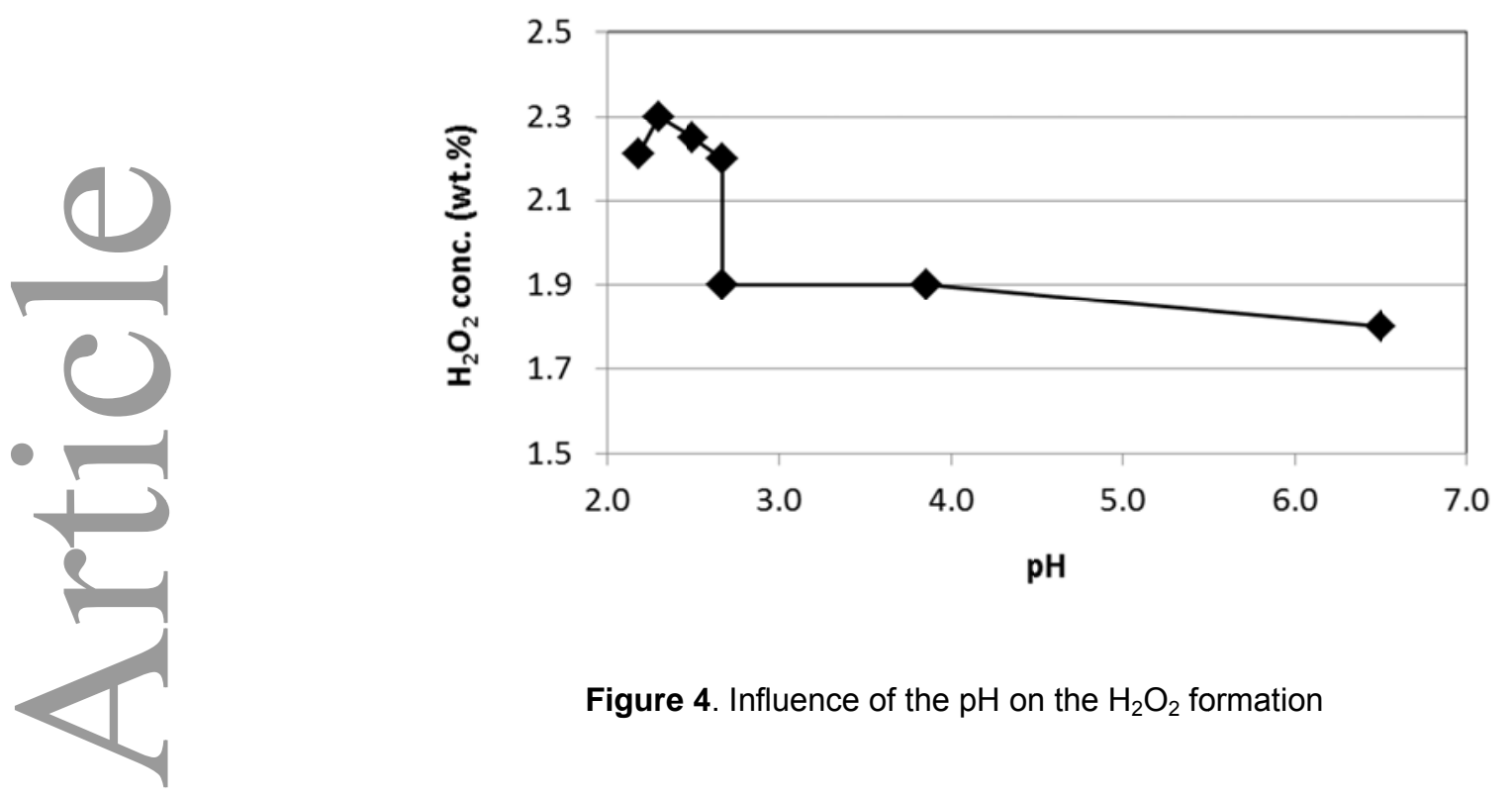

Figure 4. Influence of the $\mathrm{pH}$ on the $\mathrm{H}_{2} \mathrm{O}_{2}$ formation

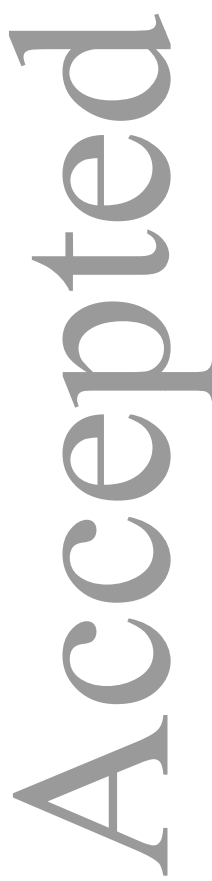




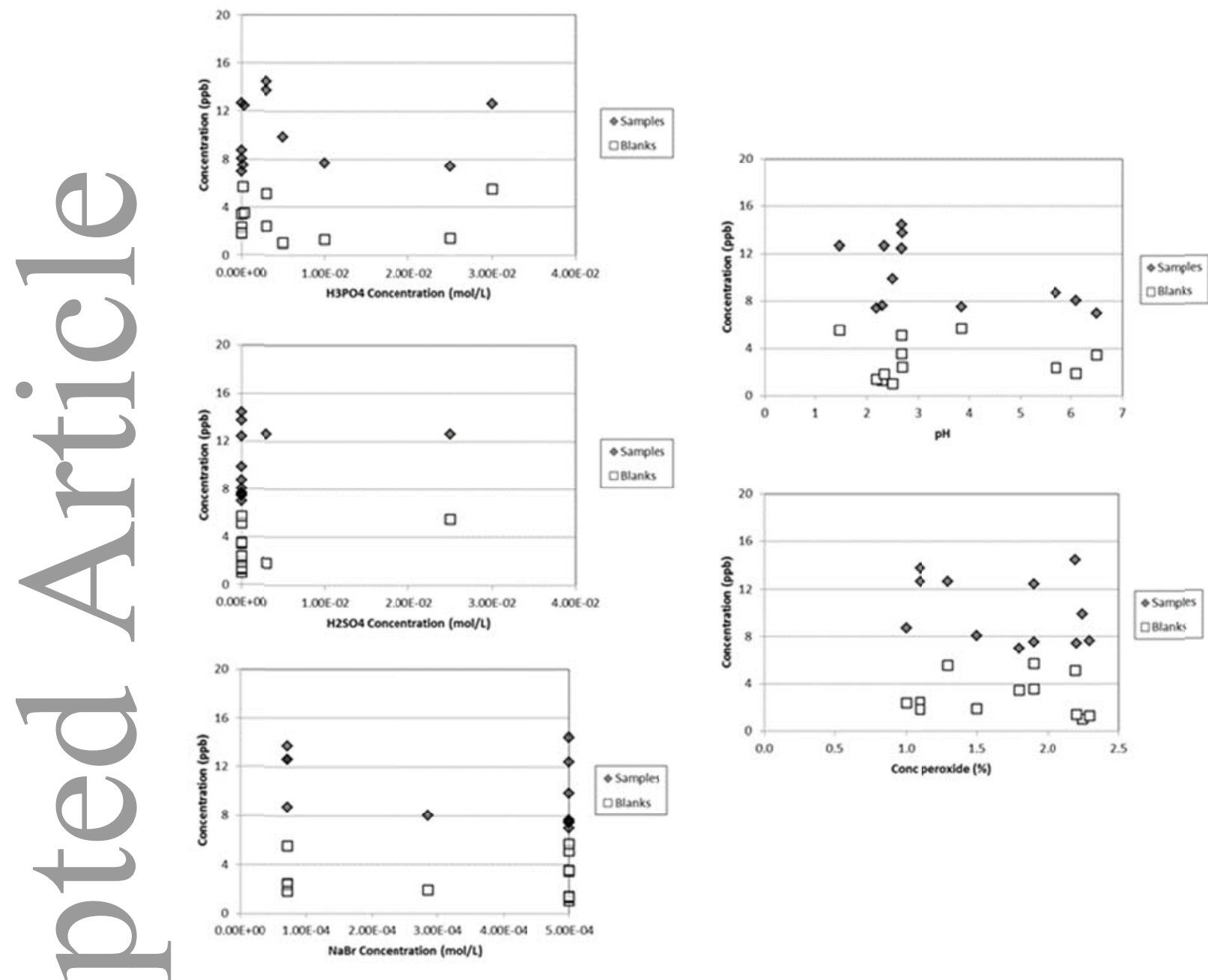

Figure 5. Influence of the main experimental variables $\left(\mathrm{H}_{3} \mathrm{PO}_{4}, \mathrm{H}_{2} \mathrm{SO}_{4}\right.$ and $\mathrm{NaBr}$ concentrations) and the resulting conditions ( $\mathrm{pH}$ and hydrogen peroxide concentration) over the boron concentration in the obtained hydrogen peroxide. 


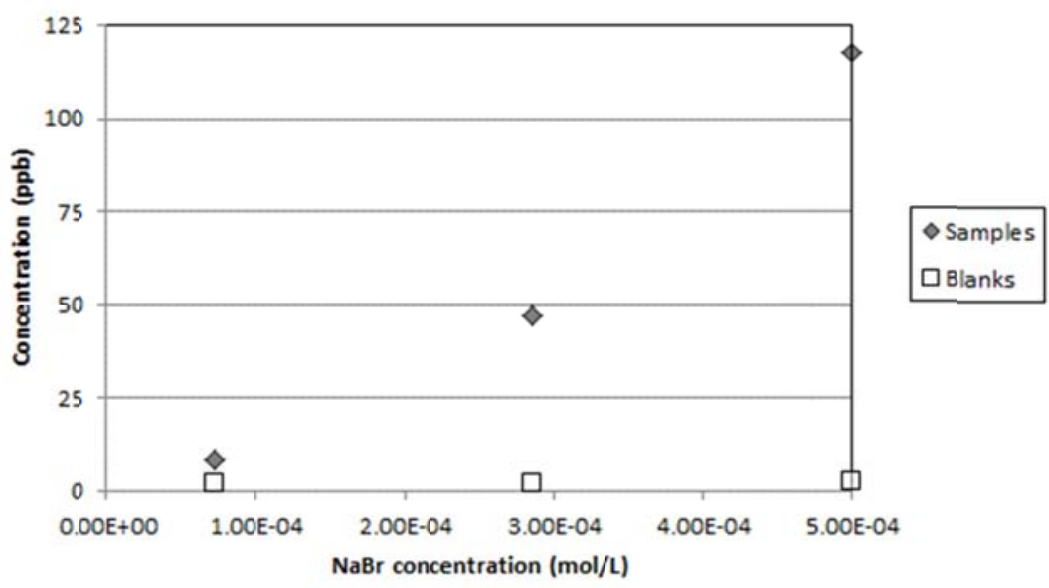

Figure 6. Influence of the $\mathrm{NaBr}$ concentration over the palladium concentration in the obtained hydrogen peroxide.

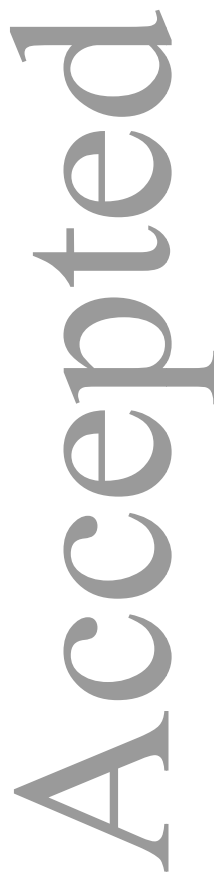



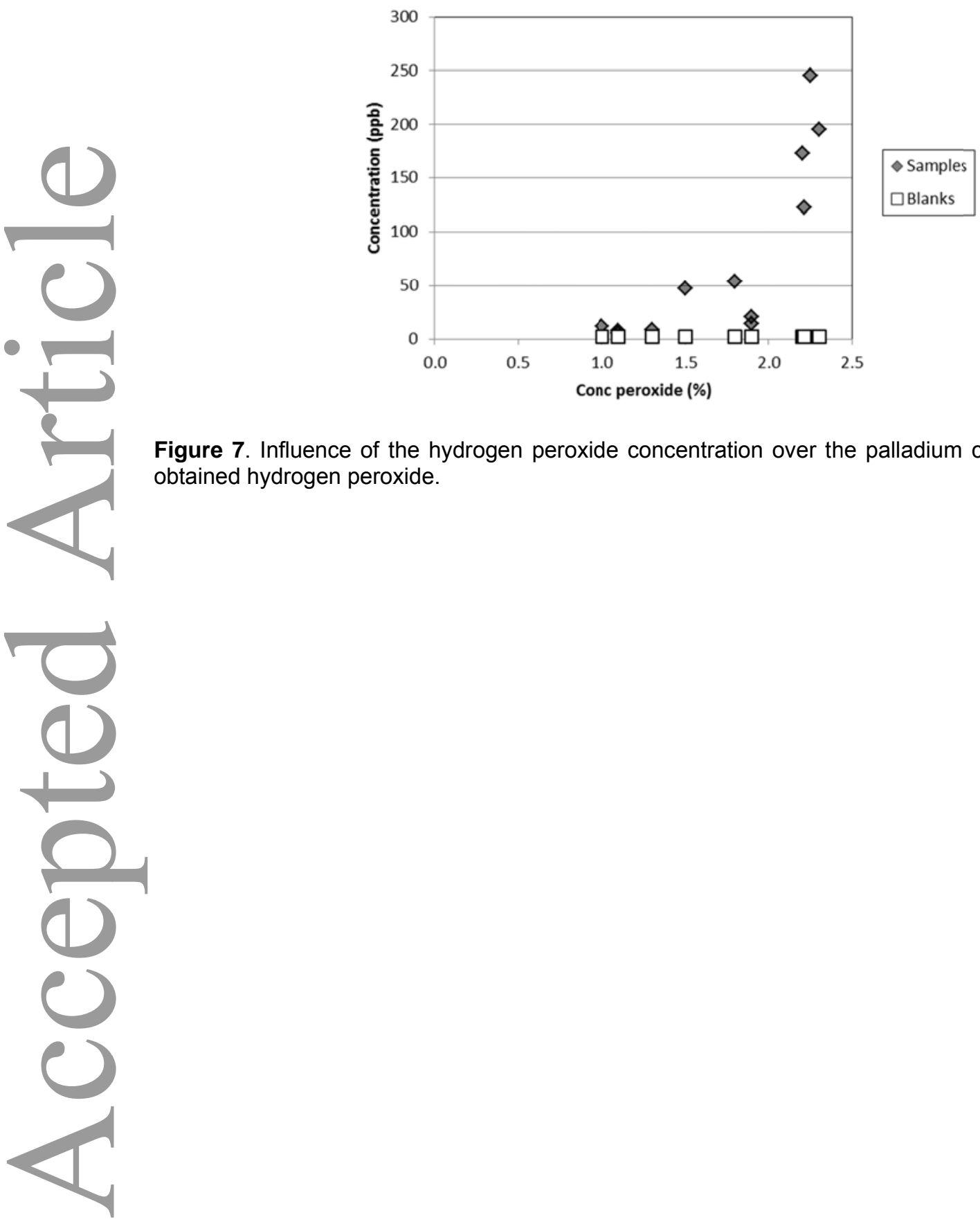

Figure 7. Influence of the hydrogen peroxide concentration over the palladium concentration in the obtained hydrogen peroxide. 

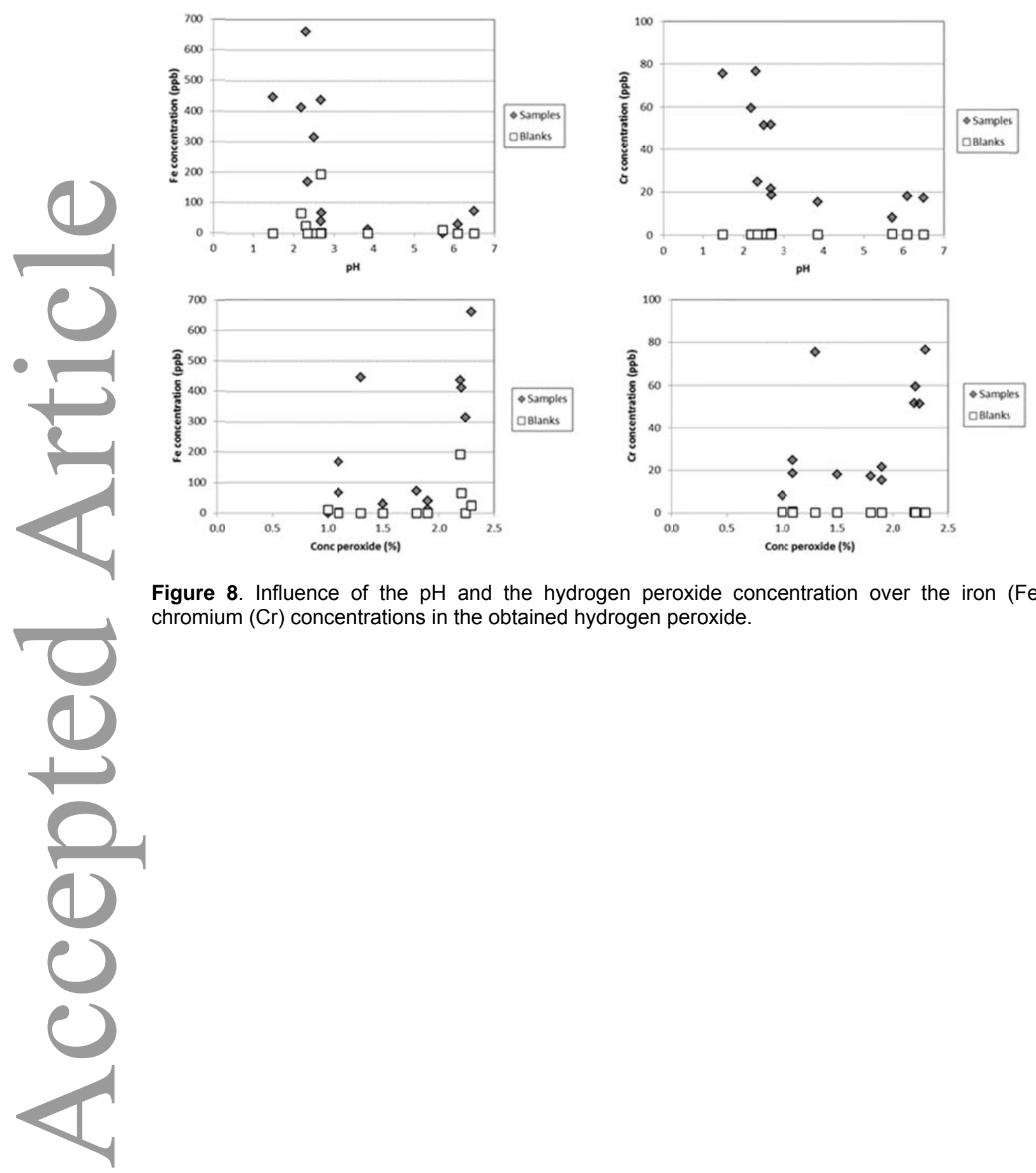

Figure 8. Influence of the $\mathrm{pH}$ and the hydrogen peroxide concentration over the iron ( $\mathrm{Fe})$ and chromium $(\mathrm{Cr})$ concentrations in the obtained hydrogen peroxide. 


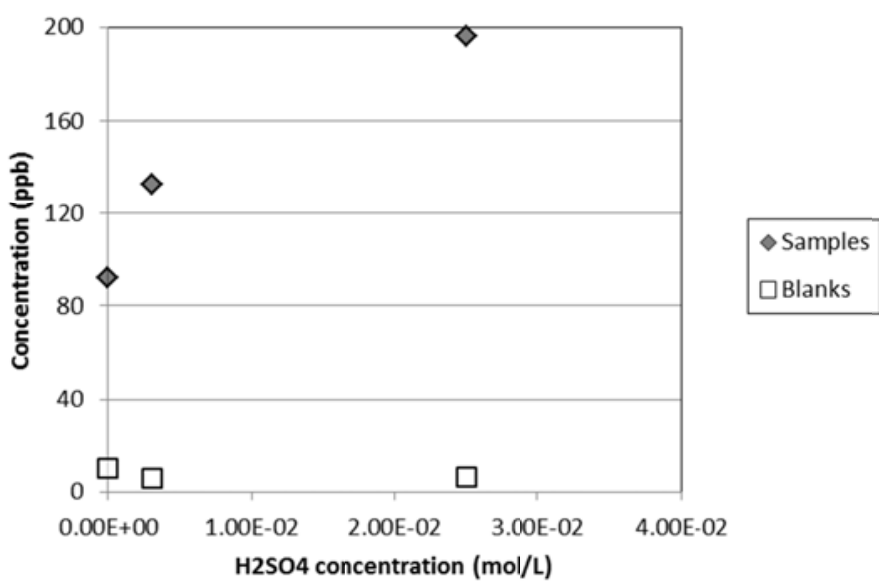

Figure 9. Influence of the $\mathrm{H}_{2} \mathrm{SO}_{4}$ concentration over the aluminum concentration in the obtained hydrogen peroxide.

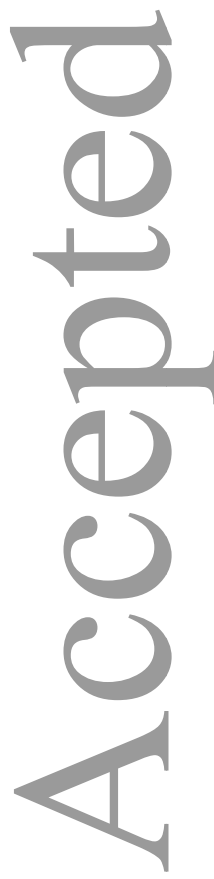




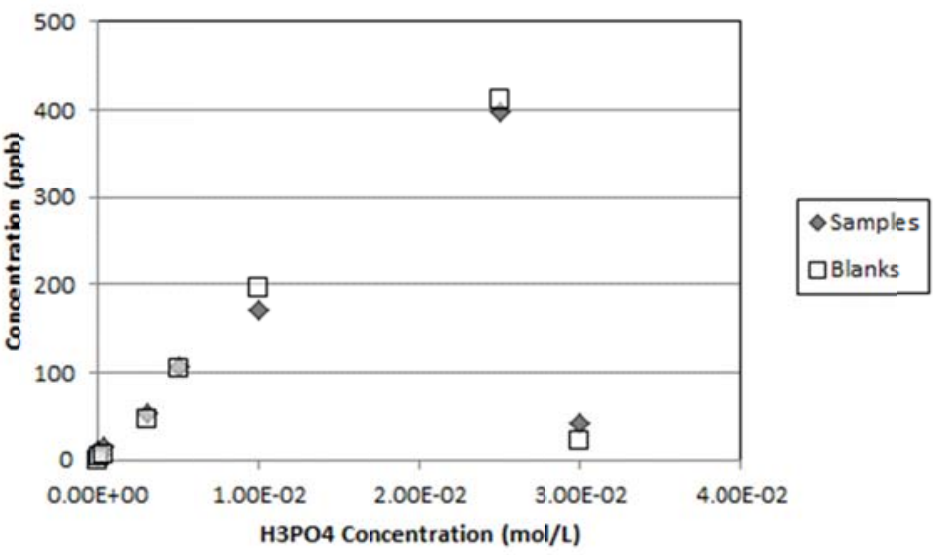

Figure 10. Influence of the $\mathrm{H}_{3} \mathrm{PO}_{4}$ concentration over the titanium concentration in the obtained hydrogen peroxide.

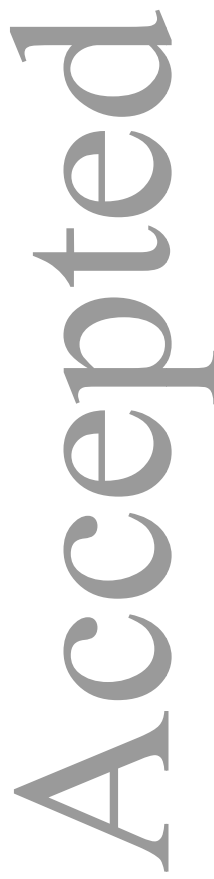




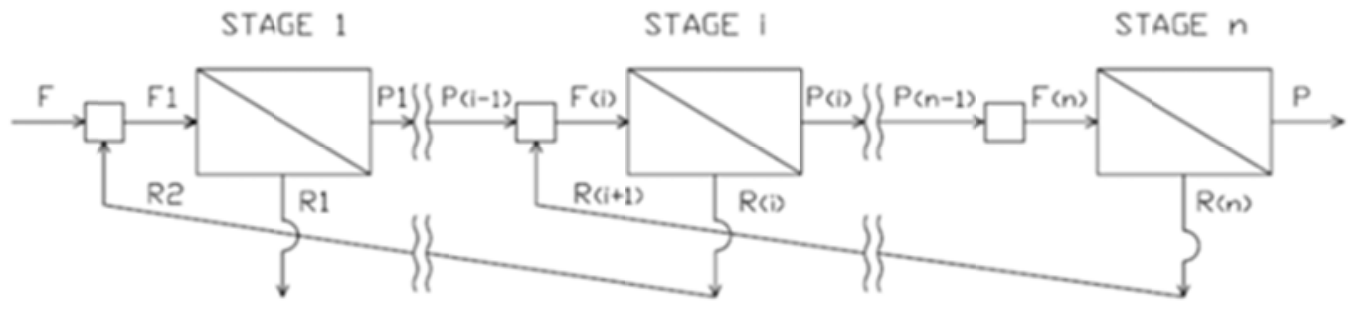

Figure 11. General scheme of an integrated countercurrent membrane cascade comprising $\mathrm{n}$ stages.
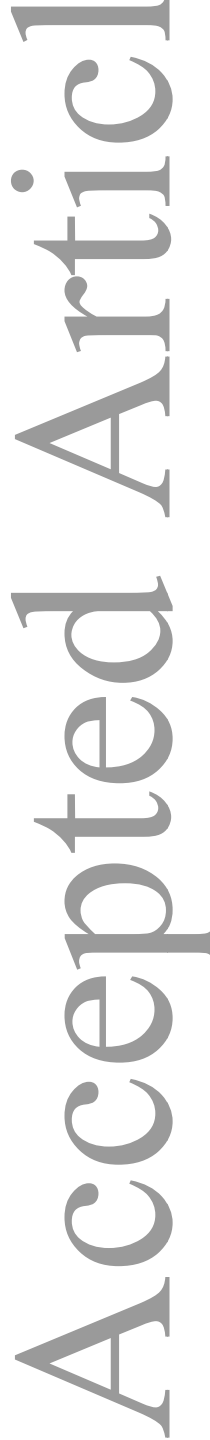